\title{
The lithosphere and asthenosphere of the Iceland hotspot from surface waves
}

\author{
Ingi Thorleifur Bjarnason $^{1}$ and Harro Schmeling ${ }^{2}$ \\ ${ }^{1}$ Institute of Earth Sciences, University of Iceland, Sturlugata 7, IS-101 Reykjavik, Iceland. E-mail: ingib@raunvis.hi.is \\ ${ }^{2}$ Institute of Earth Sciences, J. W. Goethe University Frankfurt Altenhöferallee 1, D-60438 Frankfurt am Main, Germany
}

Accepted 2009 February 11. Received 2009 January 28; in original form 2007 June 22

\section{S UM M A R Y}

1-D models were calculated for the velocity of shear waves, polarized vertically $(S V)$ and horizontally $(\mathrm{SH})$ from dispersed Rayleigh and Love surface waves. These had been recorded in Iceland by the ICEMELT broad-band seismic network, with about half of the waves coming from near-distance earthquakes $(\leq 1000 \mathrm{~km})$. The analysis included unusually short periods, as brief as $5.0 \mathrm{~s}$, and periods ranging up to $93 \mathrm{~s}$. The Icelandic crust was revealed to have two basic layers: first, the upper and middle crust, which were largely detected as one layer, and second the layer of the lower crust. The half of Iceland surveyed had a weighted average crustal thickness of 25-26 km, less than previously estimated. It is under East and East Central Iceland that the crust is thickest, averaging 29-32 $\pm 3 \mathrm{~km}$, and under the western margin of the West Fjords, $29 \pm 2 \mathrm{~km}$. The thinnest parts of the crust lie in West Central Iceland, $19 \pm 1 \mathrm{~km}$, and in the West Volcanic (or Rift) Zone, $19[+6 /-1] \mathrm{km}$. This study examined how thicker crust away from the rift zone can be fitted with dynamic crust formation models. Possible explanations for different thicknesses include both crustal squeezing flow and imbalances between widths of the volcanic accretion and extensional stretching zones. The crust has highly anisotropic zones, with differences of up to 20 per cent between $S V$ and $S H$ velocities. Under rift zones, the lower crust is characterized by low velocities and, at depths of $8-18 \mathrm{~km}$, by a channel with yet lower velocities. The lowest shear velocity in this channel is 5-9 per cent less than in the standard Icelandic velocity model. The thinnest lithosphere, $20 \pm 2 \mathrm{~km}$, lies under the East Central and North Volcanic Zones, where it extends up into the crust, while the thickest lithosphere is under East Iceland and the east shelf, nowhere less than $100 \pm 20 \mathrm{~km}$. This substantial contrast in lithosphere thickness of some $80 \mathrm{~km}$ occurs within a lateral distance of 100-150 km, implying an age unconformity at depth of several tens of millions of years. The thick East Iceland lithosphere may reduce or obstruct any eastward flow of the plume head. On the opposite side of the plume head, in Northwest Iceland and the West Fjords, the lithosphere is estimated to be $60 \pm 10 \mathrm{~km}$ thick. Excepting the West Fjords and East Iceland, shear wave velocities are low in the island's subcrustal mantle, up to 7-9 per cent below the world average according to the PREM model. This indicates a warm, partially molten mantle under much of Central Iceland and the active rift zones. There is a lateral difference of 10 12 per cent in shear velocity between the shallowest mantle asthenosphere under Central Iceland and under the mantle lid to each side, that is, under the West Fjords and East Iceland. In the shallowest Central Iceland mantle, $V_{p} / V_{s}$-ratios suggest near solidus temperatures and a partial melt of 2-3 per cent. This paper describes structural variations in the asthenosphere down to $75-200 \mathrm{~km}$. The low-velocity zone found 100-125 km below Central Iceland and the major part of western Iceland is interpreted as the onset of mantle plume melting. Mantle anisotropy is pronounced beneath Iceland, with $S H$ and $S V$ velocities differing by up to 10 per cent. The anisotropy structure is 3-D and normally reaches higher values in the asthenosphere than in the mantle lid. The main factor determining the asthenosphere's generally azimuthal anisotropy may be the lattice-preferred orientation (LPO) induced by flow. Based on this interpretation and the observed anisotropy, it follows that the plume head is flowing westwards at a depth of $60-110 \mathrm{~km}$. The deeper, more pervasive North Atlantic flow is towards 
the northwest, leading to differential shearing. However, LPO anisotropy alone would perhaps remain under 8 per cent, without the contributing factor of systematic melt distribution.

Key words: Surface waves and free oscillations; Seismic anisotropy; Mid-ocean ridge processes; Hotspots; Crustal structure; Atlantic Ocean.

\section{INTRODUCTION}

The subsurface landscape of the earth's plates, in contrast to the undersurface of icebergs, does not resemble the forms appearing above surface. At its surface, Iceland serves as an excellent place to observe how plates drift apart and how the resulting gaps are filled so as to form the country's complex volcanic landscape. This paper, however, focuses downwards, on the no less complex, subsurface landscape of these plates and on the mass of softer but mostly solid asthenosphere on which they float.

Being situated on the Mid-Atlantic Ridge, Iceland provides a unique opportunity to study the interaction between a plume and such an overriding oceanic ridge. Admittedly, identifying the seismic anomaly beneath Iceland (Wolfe et al. 1997) with a plume has recently been challenged (e.g. Foulger 2002), but whether or not it is called a plume (as it is in our study), this seismically slow mantle material is commonly assumed to be anomalously hot, wet or both. Where material of these sorts rises to shallow depths near an oceanic ridge, melt production is expected to become vigorous and anomalous (e.g. White 1997). Following this hypothesis, along with interpretations of seismic refraction, surface waves, and gravity (Darbyshire et al. 1998; Darbyshire et al. 2000a; Allen et al. 2002a; Fedorova et al. 2005), the Central Iceland crust above the postulated plume is estimated to be as thick as $41-46 \mathrm{~km}$. Towards the northwest peninsula (the West Fjords), Moho depths decrease to values of $28-35 \mathrm{~km}$ and towards the east coast (the East Fjords) to $30-35 \mathrm{~km}$ (Fig. 1). Foulger et al. (2003) have proposed that the Iceland-type crust extending from East Greenland to the Faeroe Islands is generally $\sim 30 \mathrm{~km}$ thick, and that the Central Icelandic crust is thicker because of current crustal production adding onto an older fragment of the thick Icelandic type of oceanic plate.

In an earlier seismic refraction study (RRISP), Gebrande et al. (1980) charted the seismic structure of Central Iceland with considerable resolution and then estimated the crustal thickness as $\sim 10 \mathrm{~km}$ (thin crust). This crust was interpreted to be underlain by anomalous slow mantle with compressional velocities of only $7.0-7.4 \mathrm{~km} \mathrm{~s}^{-1}$, down to a resolved depth of $\sim 30 \mathrm{~km}$. While this RRISP study did not find any Moho reflections from what could be interpreted as a shallow boundary of the crust and mantle (BCM), reflections were observed from a thin, higher-velocity layer $\left(7.8 \mathrm{~km} \mathrm{~s}^{-1}\right)$ at about $30 \mathrm{~km}$ depth. In a later analysis by Menke et al. (1996), these RRISP data were found to be consistent with a thick crust.

For modelling this thick crust, the main constraints come from wide-angle-reflections (WAR) in seismic refraction experiments and from teleseismic receiver function analysis. Most Icelandic seismic refraction data are unreliable for determining crustal thickness, since they do not include the accompanying $P n$ phase, that is, the compressional wave refracted just under the crust, and assume the WAR to be a Moho reflection. So far, most refraction experiments have used profiles that were too short for ascertaining sub-Moho velocities $(P n)$ below a relatively thick crust, that is, a crust averaging over $25 \mathrm{~km}$ thick. Even though several receiver function studies have dealt with the BCM zone (Du \& Foulger 1999; Darbyshire et al. 2000b; Du \& Foulger 2001; Schlindwein 2006), their results only agree at one location, a location in Southwest Iceland that has a significant conversion of $P$-to- $S$ at the base of the thick crust, or Moho (Schlindwein 2006).

Why the crustal thickness should decrease away from the centre of the plume is difficult to explain dynamically. Assuming that the plume flux remains constant over a given geological period, Ruedas et al. (2004) predict equal and constant thickness on ridge perpendicular profiles on either side of the ridge for crust formed during this period. One potential explanation for the Icelandic crust becoming thinner with increasing distance from the plume centre would be time-dependent rates of magma generation. Another explanation might be viscous relaxation (with spreading parallel to the ridge) as crust travels away from the accretion zone. However, such a relaxation would require a significant horizontal shear flow and a highly ductile lower crust (see e.g. Buck 1991). Recent dynamic models by Schmeling \& Marquart (2008), on the other hand, do present scenarios in which an anomalous crust may thicken with increasing distance from the ridge. Moreover, Ruedas \& Schmeling (2008) have explored the physical parameters of how an anomalous spreading ridge may lead to either a thinning or thickening of the crust away from the rift zone, depending on the ratio between the width of the crustal accretion zone and that of the crustal deformation zone. Any future dynamic interpretation of the Icelandic plume-ridge interaction will demand a reliable picture of crustal thickness variations and the lithospheric structure.

This paper introduces the analysis of Icelandic seismic data. In addition, it attempts to identify the island's stratification and the thickness of its crust and lithosphere, in fact revising its crustal and lithospheric structure. Asthenosphere structure is analysed to a depth of $\sim 200 \mathrm{~km}$. Unless otherwise stated, the term 'lithosphere' will refer to the 'seismic lithosphere'. Although the asthenosphere acquires its characteristics through long-term rheological weakening, the physical properties involved correlate well with measured reductions in seismic velocity. Therefore, unless stated otherwise, the term 'asthenosphere' will mean the seismic low-velocity zone beneath the lithosphere.

\section{DATA AND ANALYSIS}

The fundamental results of this paper, which are used in further analysis to determine velocity structure, are derived from series of Love and Rayleigh wave dispersion measurements between pairs of stations (the two-station method) within the ICEMELT broadband seismic network (Bjarnason et al. 1996a,b) (Fig. 2). The surface waves were measured with identical instruments using three-component Wielandt-Streckeisen STS-2 broad-band seismic velocity sensors. Data were digitized and temporarily stored on site with Reftek recorders. The network was installed in 1993-1995 with maximum of 15 operating stations. Stations were kept operational until the autumn of 1996. The surface wave sources used are from earthquakes mostly at a regional distance in the North Atlantic Ocean, and approximately half are within near distance range $(\leq 1000 \mathrm{~km}$, Fig. 1$)$. The short distance to these sources and rather uniform oceanic paths between them and Iceland made it 


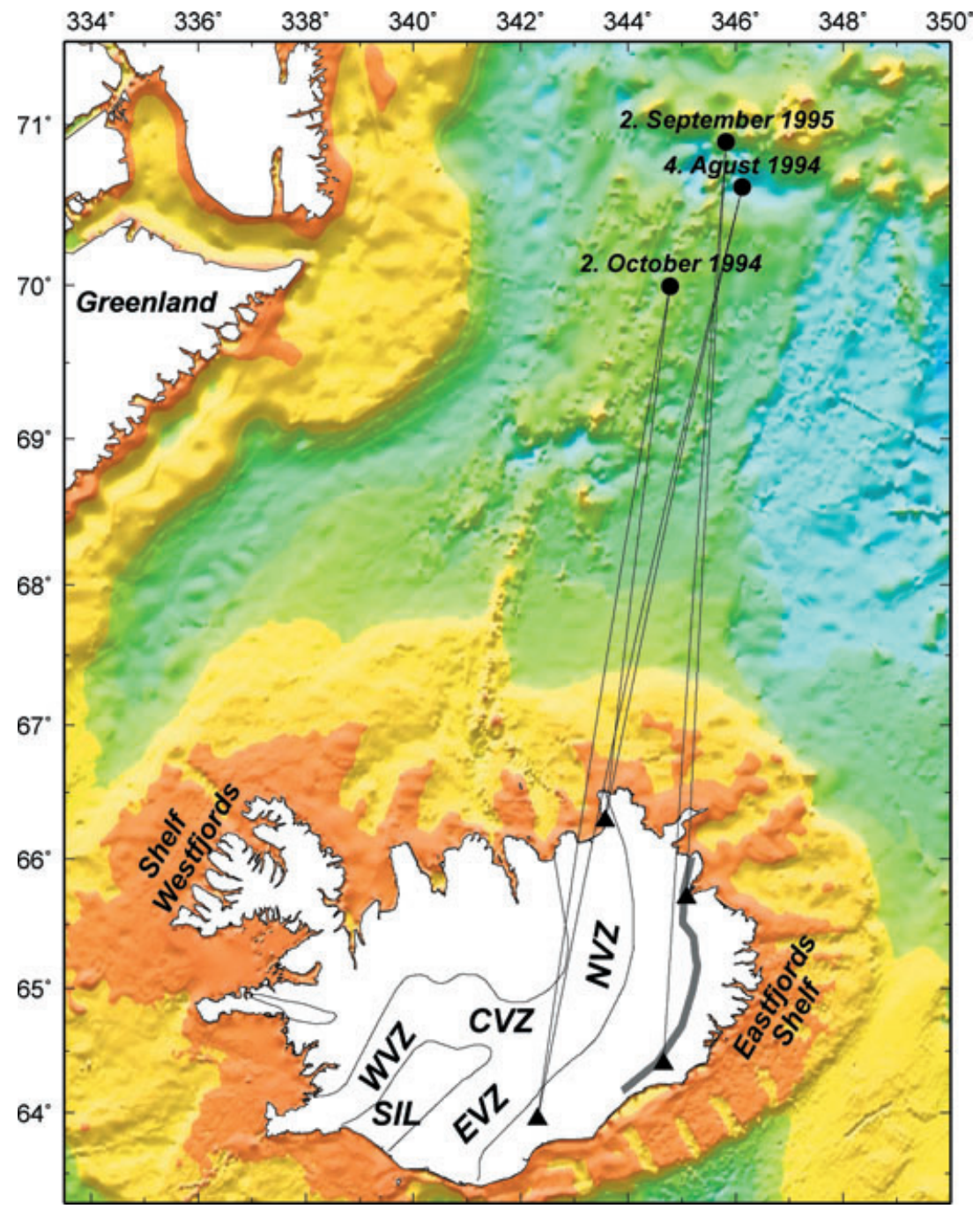

Figure 1. Examples of near distance earthquakes on the Kolbeinsey ridge and the Jan Mayen fracture zone, and their great circle paths to a subset of stations in the ICEMELT network (triangles). Segments of the neovolcanic rift zone are the West Volcanic Zone (WVZ), the East Volcanic Zone (EVZ), the Central Volcanic Zone (CVZ) and the North Volcanic Zone (NVZ). An unconformity is labeled with a dark grey line in East Iceland. Notice how it has a similar orientation to the east segments of the neovolcanic rift zone. Seafloor topography by Smith \& Sandwell (1997).

possible to analyse the simpler waveforms to a higher frequency than normally. The waves analysed are mostly of periods between 5.0 and $60 \mathrm{~s}$ for Rayleigh and 5.0-40 s for Love, respectively, and reaching up to 85-93 s for both wave types along the longer paths of Central Iceland.

The average phase velocity and its bootstrap 95 per cent confidence interval for Love and Rayleigh, was calculated for each period from 10 to 23 individual dispersion curves, depending on the source-receiver coverage for each path. The average phase velocity of each period is based on a minimum of 3 and a maximum of 14 values from the individual dispersion curves. Periods with fewer measurements are discarded unless they lie as close neighbours between periods with 3 or more measurements and their values form a smooth bridge on the curve (Fig. 3).

The average curve of each station pair or group of station pairs within one region is inverted to give two one-dimensional (1-D) velocity models for that region, with separate inversion for shear waves polarized vertically (SV) and horizontally ( $\mathrm{SH}$ ). An iterative least squares inversion for a 1-D shear velocity as a function of depth was calculated with programs of Russell et al. (1988) and Herrmann (1984-1991) to fit the observed dispersion. The shallowest crust is laterally averaged over $20-50 \mathrm{~km}$ (mostly due to off great circle paths) and the models cover approximately half of the Iceland's crust. The mantle at $200 \mathrm{~km}$ depth is averaged over a $130-170 \mathrm{~km}$ wide zone along the paths $(1 / 3$ of the width of the 1 st Fresnel zone, as proposed by Yoshizawa \& Kennett 2002). The averaging of the longer period waves, will extend to structures under the Westfjords (WF) and Eastfjords shelves (Fig. 1). The models cover close to 100 per cent of the Iceland's mantle at $100 \mathrm{~km}$ depth. As the seismic structure is interpreted with a multiple of 1-D models, 100 per cent coverage does not imply full 3-D representation. The main unmeasured parts are along the north and south coasts, the South Iceland Lowlands (SIL), and West Iceland, west of the volcanic zone (Fig. 1). Waves along northsoutherly paths, are assumed to sample a similar subsurface geology ('pure paths') due to along isochronal position of the past or present ridge segments and an 1-D velocity model may therefore give a better structural representation for these paths. Similarly, eastwesterly paths of this study can be assumed to be 'none-pure paths', where average representation in 1-D model may not correspond as well with real structure.

The surface waves in general, do not resolve a Moho as such, but in this study a change in the velocity gradient is used to define the 


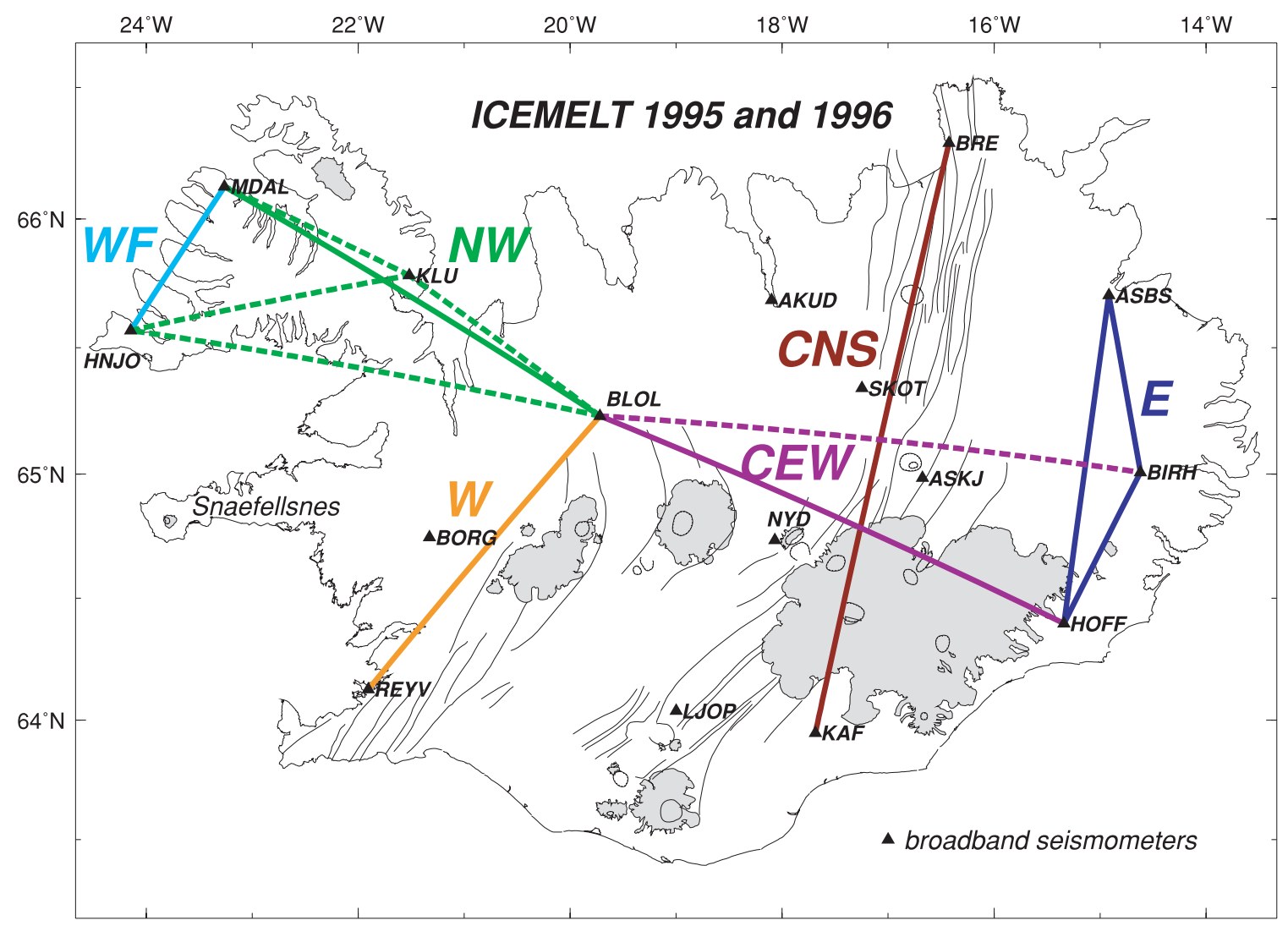

Figure 2. Station coverage (triangles) of the ICEMELT broad-band seismic network in 1995, in addition to the station BORG within the Global Seismographic Network. The network was put up in stages from 1993 and taken down in 1996 September-October. Colour lines schematically represent two-station paths, and abbreviated code names for regions they sample: WF; Northwest Iceland (NW); West Iceland and the West Volcanic Zone (W); Central Iceland paths with $\sim \mathrm{E}-\mathrm{W}$ azimuth (CEW); Central Iceland path with $\sim \mathrm{N}-\mathrm{S}$ azimuths (CNS), which is almost exclusively along the neovolcanic rift zone; East Iceland (E). Stippled lines indicate path segments with less coverage of individual dispersion curves.

$\mathrm{BCM}$, together with plausible values of mantle shear velocity. This is a non-traditional way of defining the BCM. The justification is twofold: (i) a traditional Moho with compressional wave velocity jump of $\sim 1.0 \mathrm{~km} \mathrm{~s}^{-1}$ has not been clearly observed in Iceland (see Appendix), and (ii) it is well known that velocity gradient is approximately an order or two of magnitude less in the subcrustal lithospheric mantle, subsequently referred to as mantle lid, than in the lower crust. The lower crustal shear velocity gradient measured with refracting body waves in Iceland is in the range $0.8-3.7 \times$ $10^{-2} \mathrm{~s}^{-1}$ (Bjarnason et al. 1993; Brandsdóttir et al. 1997; Staples et al. 1997; Darbyshire et al. 1998), compared to a gradient in the top $25 \mathrm{~km}$ of the mantle lid of $0.7-9.2 \times 10^{-4} \mathrm{~s}^{-1}$ in the global models PREM and ak135 (Dziewonski \& Anderson 1981; Kennett et al. 1995). The average velocity gradient of the lower crust of Iceland is used in the starting model, but the gradient of the mantle lid is assumed $7.7 \times 10^{-3} \mathrm{~s}^{-1}$. The ratio of the two is $2.8 \pm 0.6$ in the starting model, which is low. This is because of a significantly higher mantle-lid gradient in the starting model than in the global models. Inversion increases this ratio to $6 \pm 4$ on average, putting a sharper BCM than was in the starting model. The starting model has a change in velocity gradient from crustal to mantle values at $28 \pm 2 \mathrm{~km}$ depth. The inversion results determine a crust-mantle gradient change at depths of $19-32 \mathrm{~km}$, so it is fair to say that the starting model is not overly influential in fixing the crustal thickness a priori.

The average velocity gradient of the top of the mantle lid of the inversion solutions is $4 \pm 3 \times 10^{-3} \mathrm{~s}^{-1}$, with large vari- ance, and the velocity gradient of the lower crust is $2.5 \pm 0.8 \times$ $10^{-2} \mathrm{~s}^{-1}$. It should be noted that the relatively smooth starting model is likely to influence smoother solutions. If the BCM under Iceland is characterized by a Moho or a reduced Moho, synthetic tests show that the inversion with the current starting model may overestimate velocities at the bottom of the crust and gradients in the lower crust, but underestimate lid velocities. The effectiveness of the method designed here to estimate crustal thickness, was tested synthetically. It shows a positive correlation between the crustal thickness of the synthetic models $\left(h_{c}\right)$ and the estimated thickness from the inversion solutions $\left(h_{e}\right)$. With the limited number of test samples, linear relationship between $h_{c}$ and $h_{e}$ is not statistically significant, but neither is such a relation rejected. On average the estimated crustal thickness $\left(h_{e}\right)$ is $1.5-2.0 \mathrm{~km}$ thinner than the model thickness $\left(h_{c}\right)$. For a further description and discussion of data analysis, see Appendix.

\section{THE CRUST}

\subsection{Boundary of the crust and mantle}

The $S H$ models agree usually better with the general body wave derived structure of the Icelandic crust than the $S V$ models, except in the top $2-3 \mathrm{~km}$ of the crust. The general body wave model is based on the standard earthquake location model of Iceland, the compressional wave SIL model (Stefánsson et al. 1993), and scaled with the $V_{p} / V_{s}=1.785$ ratio. The SIL model is derived 


\section{RAYLEIGH DISPERSION}
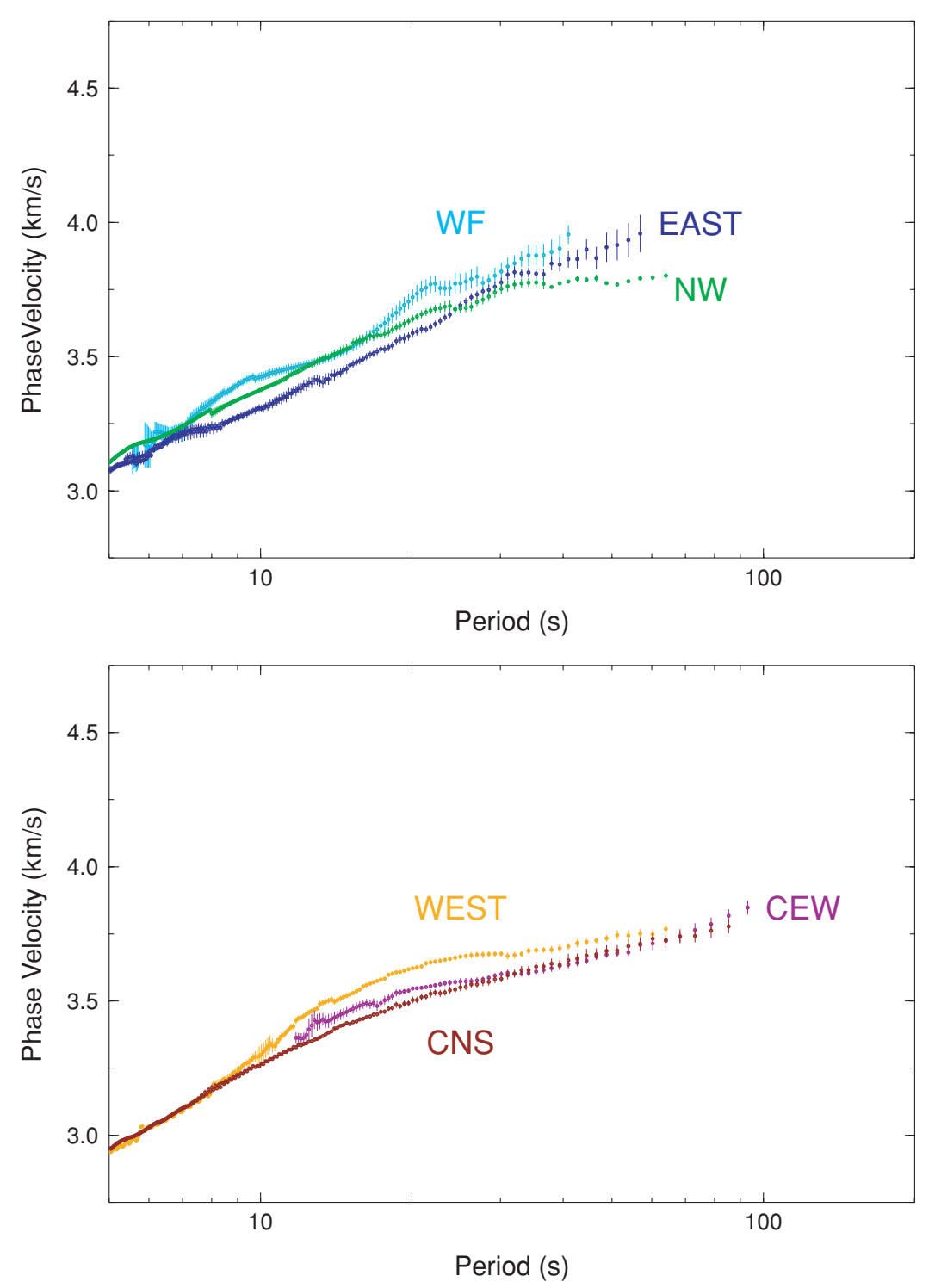

Figure 3. Average dispersion curves for s measured regions of Iceland. (a) The Rayleigh wave dispersion curves are grouped by age in two graphs. The upper graph shows the older regions WF, NW, E and the lower graph the younger regions W, CNS and CEW. See Fig. 2 for locations. For most periods the Rayleigh wave phase velocities are higher in the older regions than in the younger regions. (b) Same grouping by age for the Love waves. Below the $10 \mathrm{~s}$ period, the phase velocities are generally higher in the older regions than in the younger regions. Boot strap 95 per cent confidence intervals are shown with vertical lines through the measured periods. Table 1 contains the the number of individual dispersion curves used for the averages.

from a multiple refraction experiment (Bjarnason et al. 1993) in Southwest Iceland, and compiled for the SIL, an area of $\sim 4-$ Ma-old crust on average (Fig. 1). In the case of a crust with a predominant horizontal layer cake structure with stiff and soft layers, or soft joints between layers, the deeper penetrating crustal compressional waves that travel mostly horizontally, are more sensitive to the faster velocity layers. The Love waves are in the same way more sensitive to the stiffer and velocity faster layers. Based on these assumptions we use the $\mathrm{SH}$ models to define the main structural division of the crust and the boundary between the crust and the mantle (BCM).

The uncertainty in determining crustal thickness with a changed gradient method can be high, or up to $\pm 5 \mathrm{~km}$, but is generally $\pm 2 \mathrm{~km}$ or less. The error bars are estimated by fitting a straight line to the parts of the models with velocity gradient in the range of observed velocity gradients for the lower crust in Iceland, and a second straight line is fitted to the models there below with lower gradient, interpreted to be the mantle. Most models have a velocity gradient decrease (but also increase) within the supposed lower crust. The BCM is selected where the $S H$ velocity gradient decreases by a factor of two or more and that coincides with $\mathrm{SH}$ and/or $S V$ velocity $>4.00 \mathrm{~km} \mathrm{~s}^{-1}$. The line fits are done on the inverted model and its 95 per cent confidence models. The errors constitute the depth range of intersection of these straight lines. Higher accuracy is achieved in measuring these intersections when plotting the models in the depth range $0-100 \mathrm{~km}$, rather than $0-50 \mathrm{~km}$ or $0-200 \mathrm{~km}$ as they are presented in Figs 4 and 7, respectively. 


\section{LOVE DISPERSION}
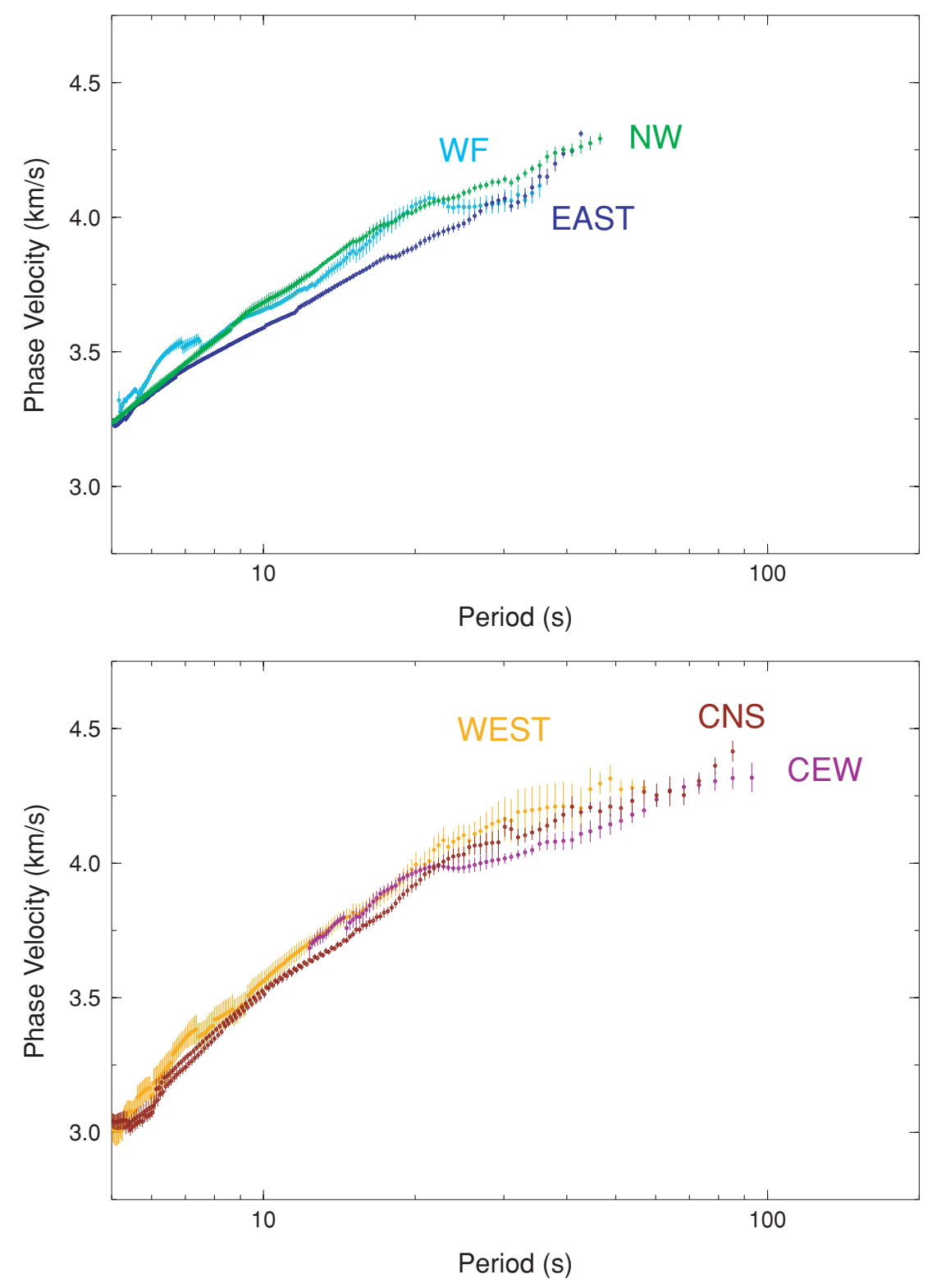

Figure 3. (Continued.)

A change in the starting model by $0.09 \mathrm{~km} \mathrm{~s}^{-1}$ (root mean squared error defined: $\mathrm{RMSE}=\left[\frac{1}{n} \sum_{i=1}^{n}\left(\left(a_{i}-b_{i}\right)^{2}\right)^{1 / 2}\right]$, leaves the depth of the BCM within the error bars. As is common in geophysics, these errors have to be regarded as minimum errors, because not all of the model space is explored. The error bars for the depth of the lithosphere-asthenosphere boundary (LAB) are determined in a similar way, but the LAB boundary is defined with the $S V$ models (see Section 5).

Approximately half of the onland crust of Iceland is measured in this study, with a weighted average crustal thickness $25-26 \mathrm{~km}$. The thickest crust is under East Iceland (E), $32 \pm 3 \mathrm{~km}$ thick $(\mathrm{SH})$ and slightly thinner, $29 \pm 2 \mathrm{~km}$ thick $(\mathrm{SH})$, under the WF (Figs 2, 4a and f; Table 1). The thinnest crust is under the Central Iceland east-west path (CEW) $19 \pm 1 \mathrm{~km}(\mathrm{SH})$ and the West Volcanic
Zone (W) $19+6 /-1 \mathrm{~km}$ thick $(\mathrm{SH})$ with very low mantle lid velocities in both provinces (Figs $4 d$ and c). For example, in the CEW province the mantle lid velocities are $S V=4.08 \mathrm{~km} \mathrm{~s}^{-1}$ and $S H=$ $4.20 \mathrm{~km} \mathrm{~s}^{-1}$, which are $\delta V_{S V}=-0.32 \mathrm{~km} \mathrm{~s}^{-1}$ and $\delta V_{S H}=$ $-0.42 \mathrm{~km} \mathrm{~s}^{-1}$ perturbations or -7.3 per cent and -9.0 per cent lower than $S V$ and $S H$ in the top $10 \mathrm{~km}$ of the mantle lid in the PREM model (Fig. 5, Dziewonski \& Anderson 1981). These low mantle lid velocities under Central Iceland allow interpreting the $10-15-\mathrm{km}$-thick mantle lid as a crust-mantle transition zone, in line with Kaban et al. (2002). However, near-solidus temperatures and melt may have similar effect on the seismic velocity of mantle material.

Although surface waves have usually less resolution than body waves, it seems that they contradict the Moho interpretation of the 

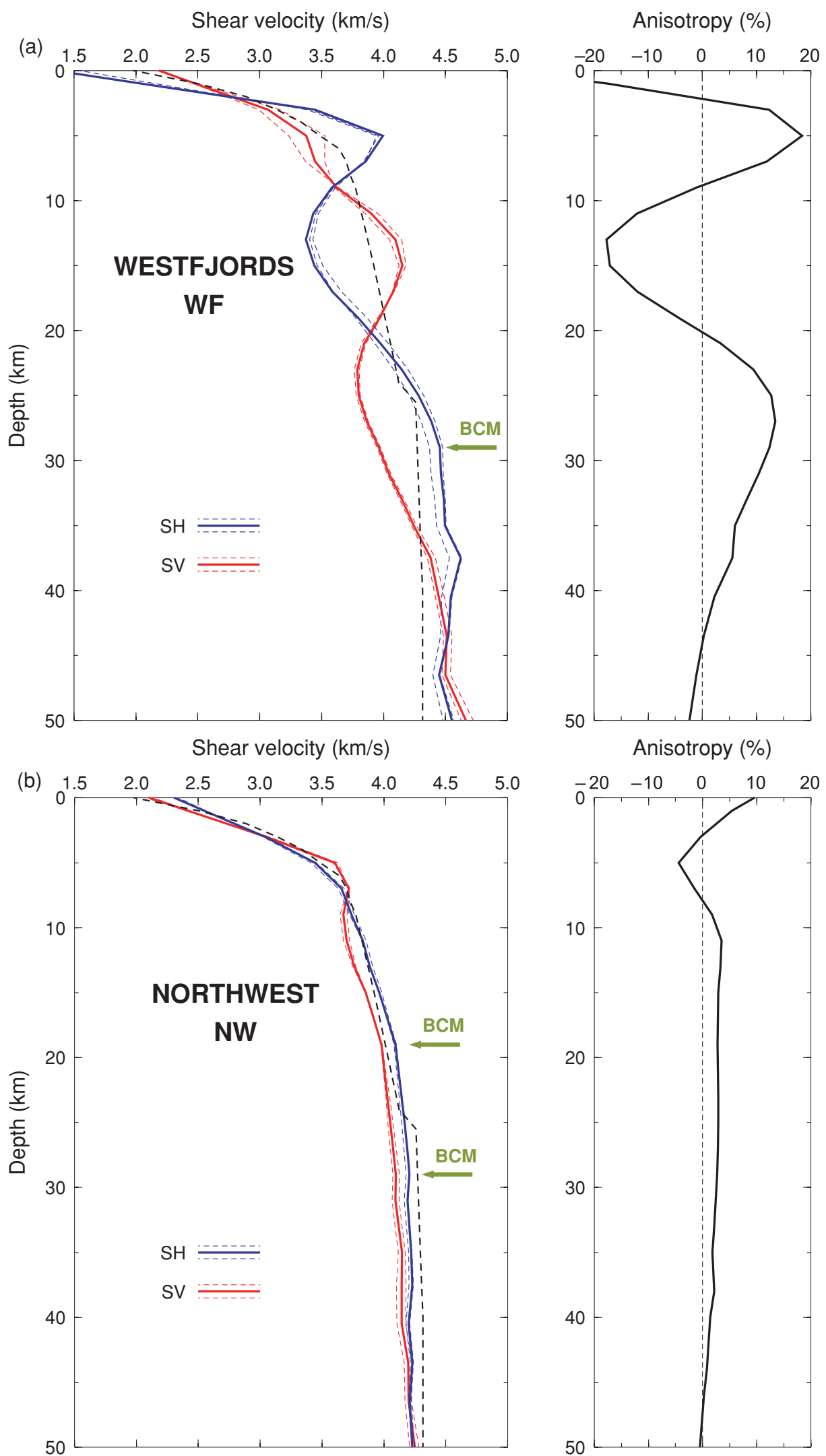

Figure 4. Velocity structure and anisotropy in top $50 \mathrm{~km}$ for the 6 measured provinces from west to east through Iceland (a-f). See Fig. 2 for profile locations. The inverted models are constant velocity layers, but plotted here with linear interpolation. The boundary of the crust and mantle is indicated (BCM) and the lithosphere-asthenosphere boundary (LAB) where it is shallower than $50 \mathrm{~km}$. The $S H$ and $S V$ velocities are shown and their 95 per cent confidence range. A modified version of the standard velocity model of Iceland (SIL model) is plotted for reference (stippled black lines). The apparent anisotropy is defined as $\left(\frac{S H-S V}{S V}\right) \times 100$ per cent. 

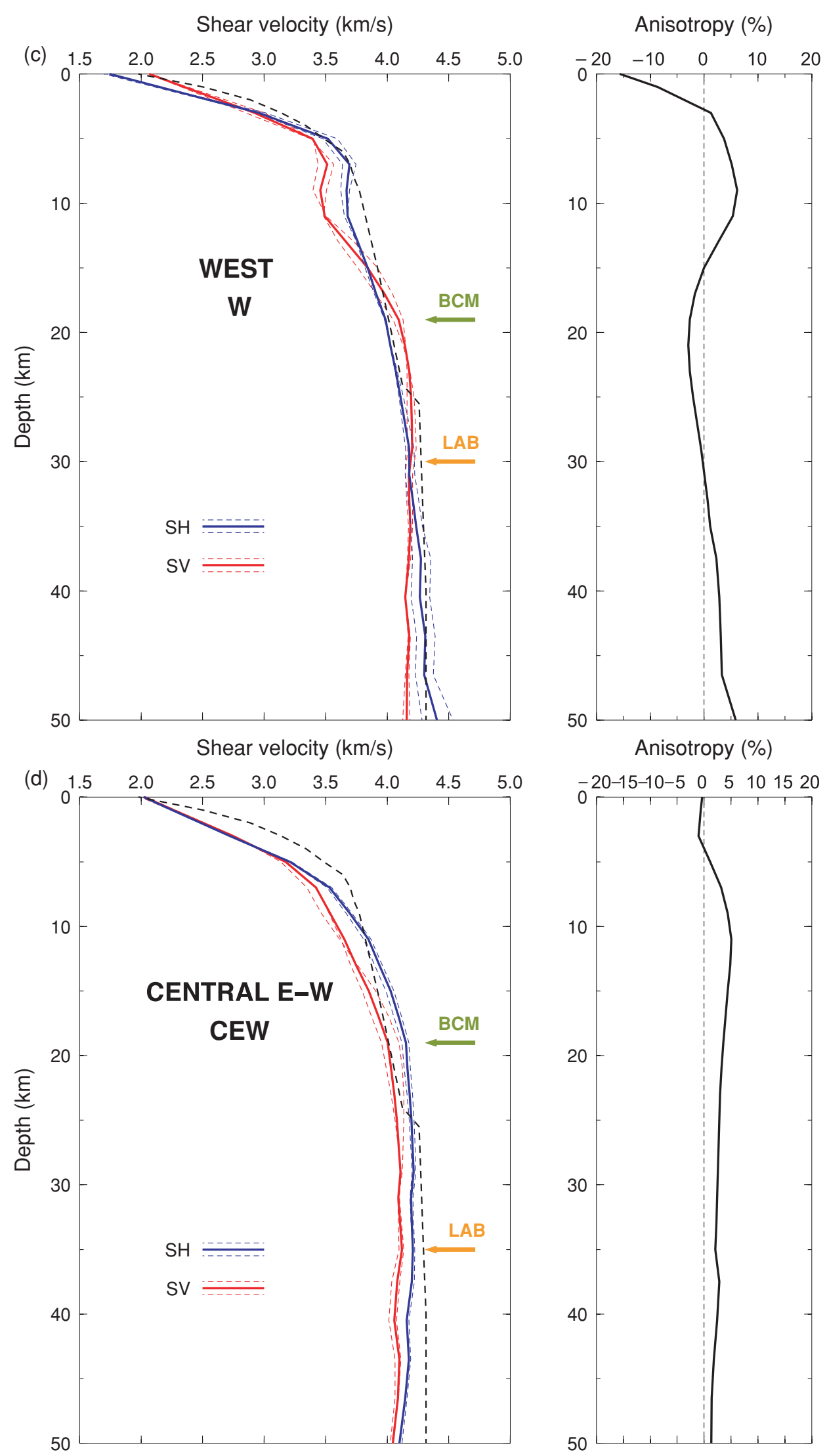

Figure 4. (Continued.) 

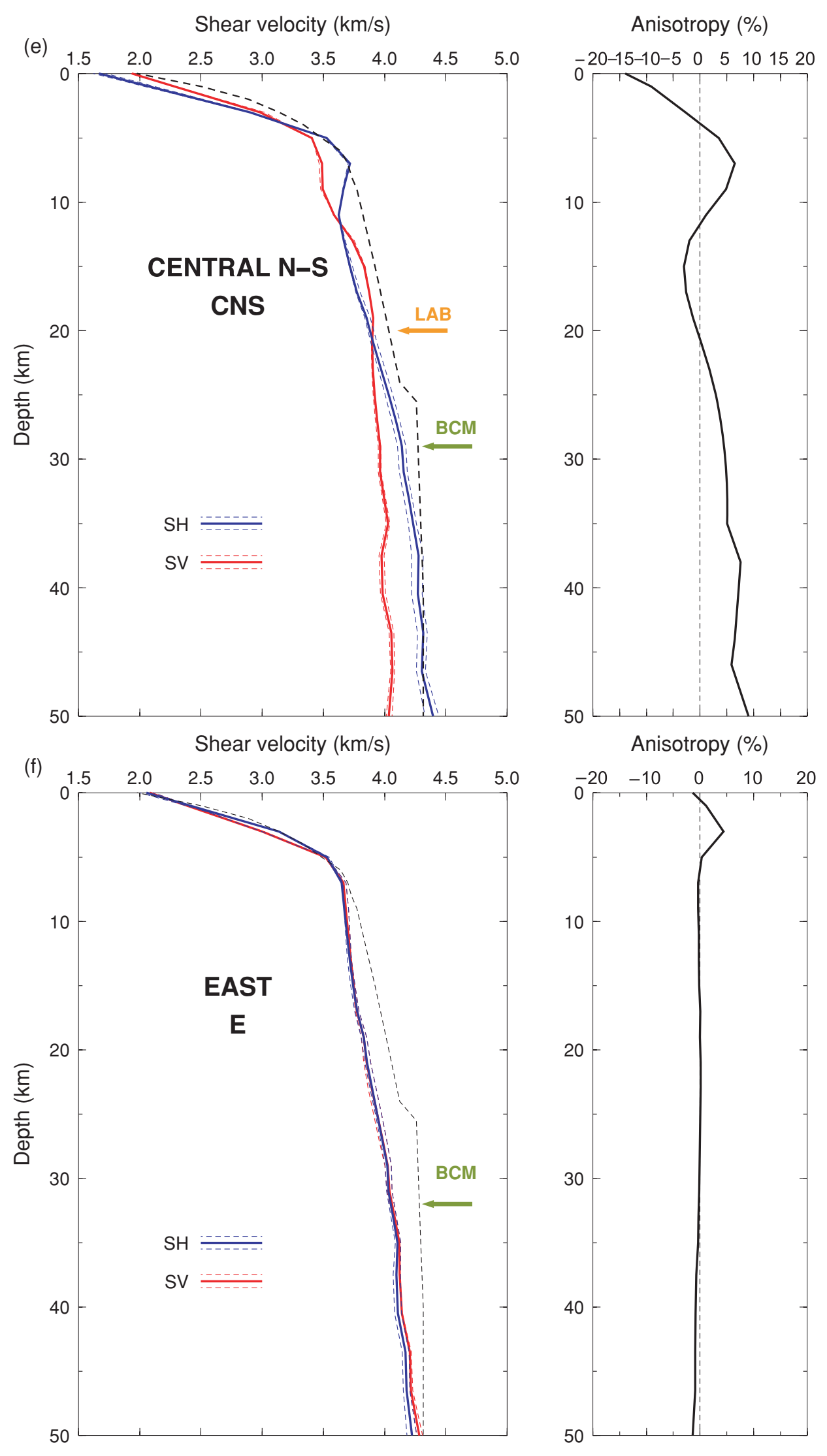

Figure 4. (Continued.) 
Table 1. Lithosphere and asthenosphere.

\begin{tabular}{|c|c|c|c|c|c|c|}
\hline Provinces & WF & NW & $\mathrm{W}$ & CEW & $\mathrm{CNS}$ & $\mathrm{E}$ \\
\hline Depth to changed $\delta V / \delta z(\mathrm{~km})$ & $5 \pm 1$ & $7 \pm 1$ & $7 \pm 1$ & $7 \pm 1$ & $7 \pm 1$ & $7 \pm 1$ \\
\hline Upper-middle crust thick. (km) & $3.7 \pm 0.1$ & $6.8+0.4 /-0.2$ & $6.4+4 /-0.8$ & $8.4 \pm 0.3$ & $6.2 \pm 0.1$ & $6.7 \pm 0.2$ \\
\hline Lower crust thickness $(\mathrm{km})$ & $25 \pm 2$ & $17 \pm 5$ & $13+1 /-4$ & $11 \pm 1$ & $23 \pm 1$ & $25 \pm 3$ \\
\hline Crustal thickness $(\mathrm{km})$ & $29 \pm 2$ & $24 \pm 5$ & $19+6 /-1$ & $19 \pm 1$ & $29 \pm 1$ & $32 \pm 3$ \\
\hline Lithosphere thickness $(\mathrm{km})$ & $55 \pm 5$ & $65 \pm 5$ & $30 \pm 3$ & $35 \pm 5$ & $20 \pm 2$ & $>100 \pm 20$ \\
\hline$S H$ at top of mantle lid $\left(\mathrm{km} \mathrm{s}^{-1}\right)$ & 4.45 & 4.16 & 3.99 & 4.15 & 4.14 & 4.05 \\
\hline Mantle lid thickness (km) & $26 \pm 7$ & $41 \pm 10$ & $11+4 /-9$ & $16 \pm 6$ & 0 & $>70 \pm 20$ \\
\hline Depth to $S H=4.15 \mathrm{~km} \mathrm{~s}^{-1}(\mathrm{~km})$ & $23 \pm 1$ & $23 \pm 2$ & $28 \pm 2$ & $19 \pm 2$ & $29 \pm 2$ & $41 \pm 1$ \\
\hline Depth to $S V=4.15 \mathrm{~km} \mathrm{~s}^{-1}(\mathrm{~km})$ & $33 \pm 1$ & $36 \pm 5$ & $21 \pm 1$ & $125 \pm 5$ & $80 \pm 7$ & $40 \pm 1$ \\
\hline$S H$ at $110 \mathrm{~km}$ depth $\left(\mathrm{km} \mathrm{s}^{-1}\right)$ & n.a. & $4.52 \pm 0.09$ & $4.38 \pm 0.11$ & $4.08 \pm 0.10$ & $4.23 \pm 0.04$ & $4.65 \pm 0.09$ \\
\hline$S V$ at $110 \mathrm{~km}$ depth $\left(\mathrm{km} \mathrm{s}^{-1}\right)$ & n.a. & $4.10 \pm 0.01$ & $4.11 \pm 0.01$ & $4.06 \pm 0.01$ & $4.10 \pm 0.05$ & $4.43 \pm 0.14$ \\
\hline Individual Love disp. & 15 & 12 & 15 & 11 & 19 & 18 \\
\hline Individual Rayleigh disp. & 11 & 10 & 16 & 16 & 18 & 23 \\
\hline
\end{tabular}
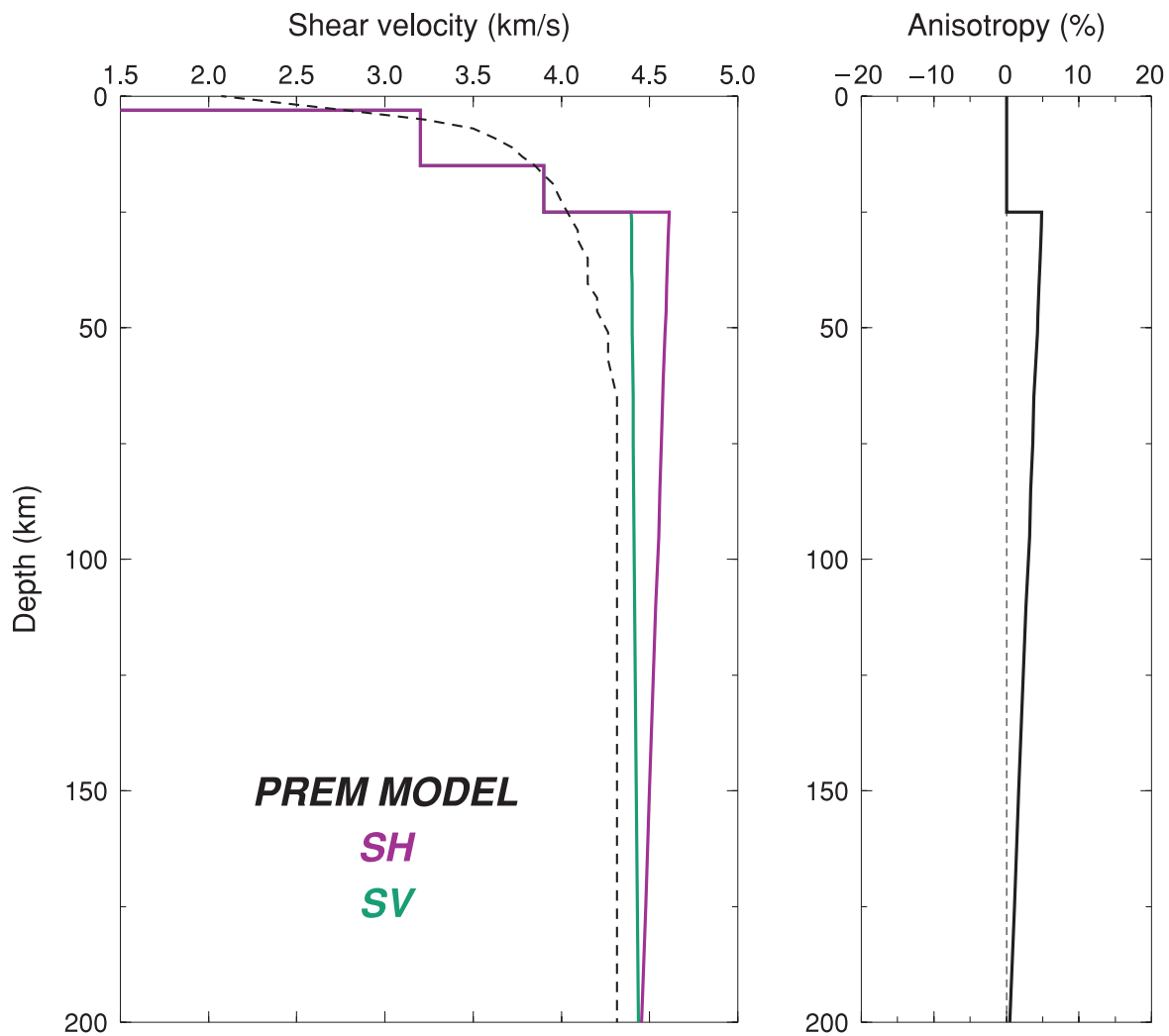

Figure 5. The top $200 \mathrm{~km}$ of the PREM model of Dziewonski \& Anderson (1981), and calculated anisotropy as defined in this work. The starting model $8 \mathrm{f}$ (stippled black line) is shown for reference.

40-km-deep wide-angle reflections (Darbyshire et al. 1998), or that of the weak discontinuity at similar depth observed with receiver functions and interpreted as a gradational crustal-mantle transition (Du \& Foulger 2001). Our analysis put these discontinuities into the mantle. A Moho or a crust-mantle transition are always associated with lower velocity on top of higher velocity. At $40 \mathrm{~km}$ depth the surface waves see higher velocity on top of lower velocity. This difference in interpretation is not a result of the non-traditional definition of BCM of this work. A correction for the structure of the E province that sample $1 / 3$ of the CEW paths, would most likely strengthen the general interpretation of the positions of the BCM and the $\mathrm{LAB}$ in the $\mathrm{CEW}$ province. The correction would increase the velocity of the mantle lid in the depth range 19-35 km and decrease the velocity of the asthenosphere below $35 \mathrm{~km}$ depth.
There are several explanations to the contrasting conclusions on the crustal thickness of Central Iceland. These include actual differences in seismological results, derived from similar data (Allen et al. 2002a), but they may also be due to different interpretation of dissimilar seismological data (e.g. Darbyshire et al. 1998; Du \& Foulger 2001). The disparity between this work and Allen et al. (2002a) could lie in a narrower period range and quite constraining starting model with a priori $\sim 40-\mathrm{km}$-thick crust in Central Iceland of the latter. In addition, this work uses Love and Rayleigh waves while Allen et al. (2002a) only use the Love wave component of the surface waves. In our view the Rayleigh waves confirm the general structure and interpretation of Central Iceland (Fig. 4d). Neither the data of Du \& Foulger (2001) or of Darbyshire et al. (1998) clearly resolve well the structure of the presumed mantle lid under the 
$\mathrm{BCM}$, which is very helpful in making a firm distinction between the lower crust and the mantle. Data exist which we believe partially supports this new interpretation. By inspecting the refraction record section from the G-shots of Gebrande et al. (1980), a Pn-like phase with apparent velocity of $7.6 \mathrm{~km} \mathrm{~s}^{-1}$ arrives at a cross-over distance of $130-150 \mathrm{~km}$. That suggests that the area north of Hekla and into Central Iceland has crustal thickness $<25 \mathrm{~km}$. The SIL area $\sim 60 \mathrm{~km}$ SW of the southern edge of Central Iceland has a confirmed crustal thickness of 21-22 km (Bjarnason et al. 1993).

Judging by the crustal thicknesses of $19 \mathrm{~km}(\mathrm{SH})$ in the W province and of $29 \mathrm{~km}(\mathrm{SH})$ in the WF province, it is clear that the NW province, that partly contains both, is not a 'pure path' province. In fact, the NW SH model has velocity gradient change at a depth of 19 and $29 \mathrm{~km}$, and both could be a candidate for the BCM (Fig. 4b). We assign an intermediate crustal thickness between the two values in the NW province of $24 \pm 5 \mathrm{~km}$, even though it is a stylistic break in the method used, as there is not a gradient change at $24 \mathrm{~km}$ depth.

The crustal thicknesses reported here agree well or moderately well with previous studies, with the exception of the new interpretation of crustal thickness of west central Iceland (intersection of the north part of W profile and west part of CEW profile). Under East Iceland, Staples et al. (1997) determined 35-km-thick crust and Du et al. (2002) 30.5-km-thick crust on average. Under the southern part of the W province, Bjarnason et al. (1993) determined a 21$22-\mathrm{km}$-thick crust and Du et al. (2002) a crust of 22-km thickness, but Du \& Foulger (2001) determined a 29-km-thick crust under the north part of the W province. Du \& Foulger (1999) determined thinner crust under the WF province, or $24.5 \mathrm{~km}$ thick on average, but Holbrook et al. (2001) reported a crust of 30-km thickness under the SIGMA 1 line on the WF shelf.

It is interesting to note that at the east and west flanks of the hotspot (i.e. West- and Eastfjords and their shelves (Fig. 1), the crust is thicker than in the central parts (Figs 4a, f and c, d). This contradicts not only the seismic results of Darbyshire et al. (1998) and Du \& Foulger (2001) but apparently also the numerical models of crust formation above a plume centred at a spreading ridge by Ruedas et al. (2004). That model assumed that crust is formed within a $60 \mathrm{~km}$ wide spreading and accretion zone above the plume centre, from which it is laterally transported away at a rate corresponding to the plate velocity. A consequence of this geometrical and kinematic assumption is a crust having its maximum thickness at the centre of the plume. In contrast, and in agreement with the seismic observations of this paper, more recent dynamic models (Schmeling \& Marquart 2008) show that differential flow within the newly formed crust may be the cause of central thinning of the newly accreted crust. In the central region crustal material is accreted in the central emplacement zone, but moves sideways with a somewhat higher velocity than the spreading velocity. This differential, squeezing-type flow is caused by the dynamic pressure in the central region due to the buoyant plume pushing from below and the accreting material pushing from above. As an example, Fig. $6 \mathrm{~b}$ shows one of these models (plume is centred at $x=0$, the model is symmetrical with respect to $x=0$ ) in which the central part of the crust (light blue) moves to the side upon thickening. Even though the crust is thinner in the central part, resulting in lower isostatic topography relative to the flanks, hot buoyant asthenosphere and dynamic stresses due to plume flow may be strong enough in this kind of models to produce an overall positive central topography. In another more kinematical approach, Ruedas \& Schmeling (2008) systematically investigate the conditions leading to lateral crustal variations near spreading centres and find that central thinning is a consequence of an imbalance between the widths of the extensional stretching zone, $w_{\mathrm{e}}$, and the volcanic accretion zone $w_{\mathrm{v}}$. Central thinning usually occurs if $w_{\mathrm{e}}<w_{\mathrm{v}}$. Thus seismic observation of a thinner central part possibly implies that crustal accretion takes place in a wider region than the rift zones, implying that the addition of magmatic material outside the rift zones is an important contribution to Icelandic crustal formation.

\subsection{Upper and middle crust}

Traditionally the crust is divided into two main layers, upper and lower crust. In Iceland the separation has been made at the depth of the velocity contour $6.50 \mathrm{~km} \mathrm{~s}^{-1}$ for compressional waves (Pálmason 1971), which also coincides approximately with a change in velocity gradient of the velocity structure (Flóvenz 1980). Lately, the upper crust has been divided into two parts, upper and middle crust (Bjarnason et al. 1993). The idea is that an ophiolite oceanic crustal model may also apply to Iceland with the upper crust being constructed mostly of volcanic extrusives and the middle crust of extrusives and sheeted dyke complexes, magma chambers and accumulates. The middle crust is intermediate in seismic properties, but usually not in the centre of the crust. In line with the nomenclature 'extrusive' and 'intrusive' crust, we propose to call the middle crust 'bitrusive' in origin. With an average thickness of only $\sim 5.0 \mathrm{~km}$ of the combined upper and middle crust (Flóvenz 1980), it is beyond the resolution of the surface waves of this study to discriminate between them. Therefore, they are lumped together. Preferably the division between the upper-middle crust and lower crust should be made with a changed velocity gradient. However, it seems that the starting model for the inversion in this work is rather influential in fixing a gradient changed at $7 \mathrm{~km}$ depth in most of the provinces (Table 1). Hence the $3.64 \mathrm{~km} \mathrm{~s}^{-1}$ velocity contour for $S H$ waves is used to define the depth to the lower crust and thickness of the upper-middle crust, and error bars correspond to the depths of this contour in the 95 per cent confidence models. This velocity contour corresponds to the compressional velocity $6.50 \mathrm{~km} \mathrm{~s}^{-1}$ and the $V_{p} / V_{s}=1.785$ ratio, the fixed value of the inversion. That value is 0.5 per cent higher than the average $V_{p} / V_{s}$ for the whole of the Icelandic crust measured so far, but very close to the average ratio of the lower crust (Pálmason 1971; Menke et al. 1996; Staples et al. 1997; Darbyshire et al. 1998; Tryggvason et al. 2002).

The thinnest upper-middle crust (extrusive and bitrusive) are under the western parts of the WF where it is only $3.7 \pm 0.1 \mathrm{~km}$ thick ( $\mathrm{SH}$ in Fig. 4a). The thickest upper-middle crust is under the CEW profile, that crosses East Iceland and the high Central Iceland, where it is $8.4 \pm 0.3 \mathrm{~km} \mathrm{~s}^{-1}$ thick ( $S H$ in Fig. $4 d$ ). Using compressional waves Pálmason (1971) on average estimated the upper-middle crust to be $4.3 \mathrm{~km}$ thick in the WF province and Holbrook et al. (2001) estimated a 5-km-thick upper-middle crust there, also using compressional waves, but not with good resolution (Reid, private communication, 2007). Darbyshire et al. (1998) measured upper-middle crust up to $8-10 \mathrm{~km}$ thick under the western half of the CEW profile with compressional waves. However, the Love wave dispersion in WF has a certain irregularity in the high frequency end that excites the inversion into extreme shallow structure, which possibly underestimates the thickness of the uppermiddle crust (Fig. 3b), and the CEW dispersion (Love) has the least high frequency coverage of all the dispersion curves. Therefore, the thickness of upper-middle crustal may be more uncertain along these profiles than elsewhere.

In the NW province (station BLOL to WF) the upper-middle crust is $6.8+0.4 /-0.2 \mathrm{~km}$ thick ( $S H$ in Fig. $4 \mathrm{~b}$ ). The $S H$ model of this 


\section{Crustal structure from seismic and dynamic modelling}
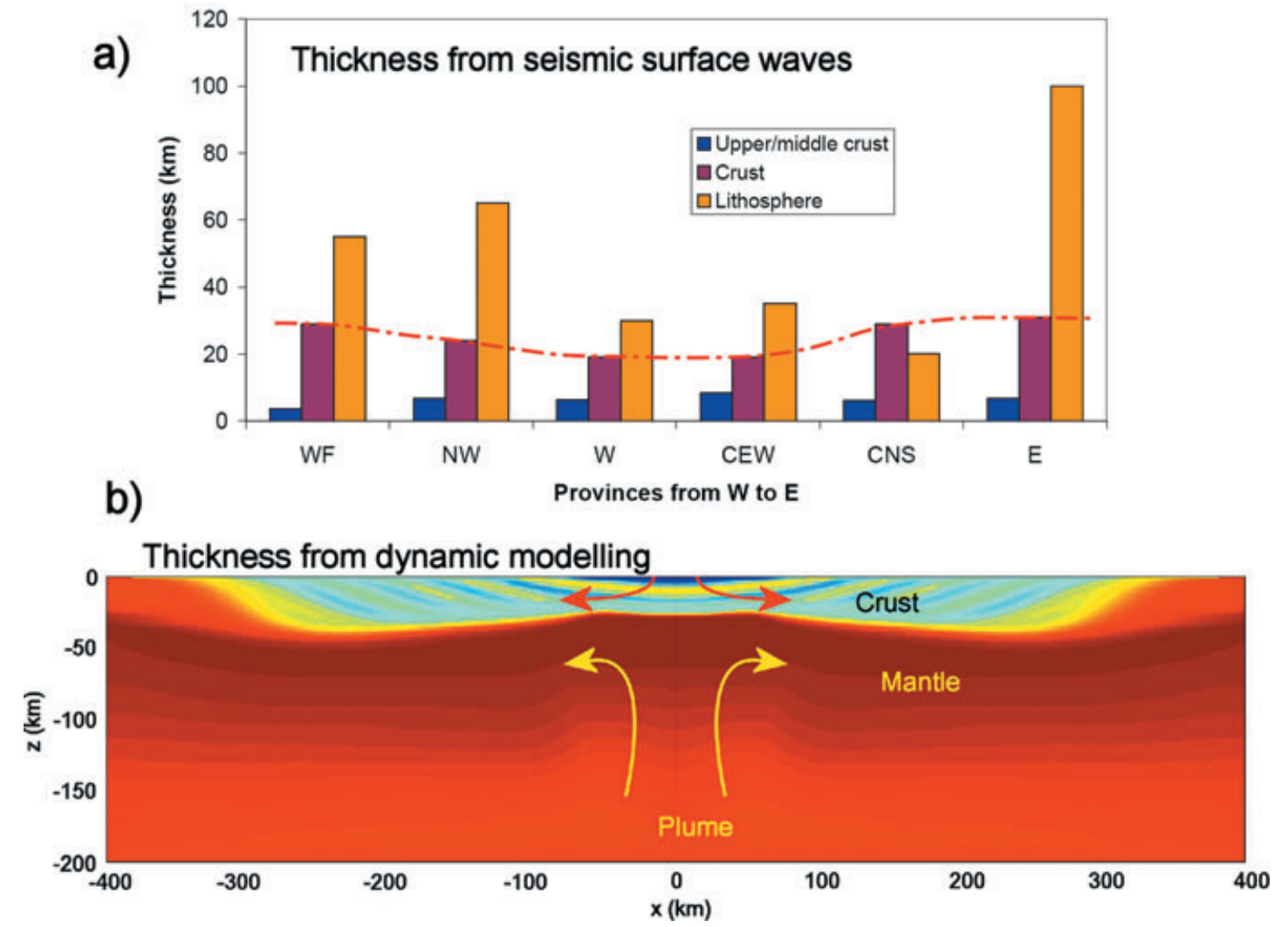

Figure 6. Comparison of the seismically derived crustal structure with a dynamic model of crust formation. (a) Summary of thicknesses of upper and middle crust, total crust and lithosphere from the seismological models. (b) Basaltic depletion and generated crust of a numerically modelled spreading zone with $1 \mathrm{~cm} \mathrm{yr}^{-1}$ spreading rate, beneath which a plume is ascending with $10 \mathrm{~cm} \mathrm{yr}^{-1}$ and $150{ }^{\circ} \mathrm{K}$ excess temperature. Melting occurs in the plume head, is extracted and fed back into the model at the top between $x=0$ and $50 \mathrm{~km}$ to generate the crust. Time is $25 \mathrm{Ma}$ after starting plume influx. Depletion values in the mantle (red) vary between 0 and 0.2 (i.e. up to 20 per cent basaltic melts are extracted in the dark red regions), blue/yellow colours represent newly formed crust, the actual colour has been varied periodically to visualize the evolution of crust formation. Note the thinning of the crust above the centre of the plume $(x=0)$ despite maximum crust generation rate there. Figure modified after Schmeling \& Marquart (2008), where more modelling details can be found.

province is the closest to the standard earthquake location model of Iceland, the SIL model. The RMSE between the NW SH model and the SIL model is $0.11 \mathrm{~km} \mathrm{~s}^{-1}$, assuming $V_{p} / V_{s}=1.785$.

The neovolcanic zones along the $\mathrm{W}$ and CNS profiles, have $6.4+4 /-0.8 \mathrm{~km}$ and $6.2 \pm 0.1 \mathrm{~km}$ thick $(S H)$ upper-middle crust respectively (Figs 4c and e), with mean thickness of $6.3 \mathrm{~km}(\mathrm{SH})$. This upper-middle crustal is on average $0-2.0 \mathrm{~km}$ thicker than those of refraction experiments that have crossed neovolcanic zones away from central volcanoes (Zverev et al. 1980; Bjarnason et al. 1993; Brandsdóttir et al. 1997; Weir et al. 2001). It does possibly indicate a higher $V_{p} / V_{s}$-ratio in the upper-middle crust of the neovolcanic zones than assumed in this study. In the CNS province both $S V$ and $\mathrm{SH}$ velocities are low throughout the lower crust, with an extra low velocity channel (velocity inversion), between 8 and $18 \mathrm{~km}$ depth. The maximum perturbation of the $\mathrm{SH}$ model from the standard SIL model in the low velocity channel is $-0.206 \mathrm{~km} \mathrm{~s}^{-1}$ or -5.3 per cent at $13 \mathrm{~km}$ depth. This is a large velocity perturbation. These $\mathrm{SH}$ velocity perturabations are similar to those observed by Allen et al. (2002a) in the same area, which they obtained from inversion of Love waveforms. The $S H$ velocities in the $\mathrm{W}$ province have also a low velocity channel in the depth range $8-18 \mathrm{~km}$, but with less perturbation than the CNS channel $\left(-0.142 \mathrm{~km} \mathrm{~s}^{-1}\right.$ or -3.7 per cent at $11 \mathrm{~km}$ depth). The $S V$ models for the top $15 \mathrm{~km}$ of the crust are very similar in the two rift zones. That is not unexpected, due to the similarity of the dispersion curves between the 5 and 9 s periods. The maximum perturbation of the ridge $S V$ models from the standard model are -7.4 and -8.6 per cent at 9 and $11 \mathrm{~km}$ depths in CNS and $\mathrm{W}$ provinces, respectively. These low velocities in the lower crust of the ridge areas need to be quantified in future studies in terms of temperature and a possible melt.

A notable asymmetry in the thickness of the upper-middle crust is observed between the WF (10-15 Ma) with $3.7 \pm 0.1 \mathrm{~km}$ thick ( $\mathrm{SH}$ in Fig. 4a) upper-middle crust and East Iceland of similar age, where it is $6.7 \pm 0.2 \mathrm{~km}$ thick ( $\mathrm{SH}$ in Fig. 4f). Even though the thickness in the WF, may have been underestimated as mentioned above, adding to this asymmetry is $0.5-1.0 \mathrm{~km}$ higher erosion of the lavapile in East Iceland than in the WF (Hjartarson and Sæmundsson, private communication, 2006). The estimated upper-middle crustal thickness of East Iceland is higher than reported by previous authors with refraction measurements: estimated $\leq 3.5 \mathrm{~km}$ by Pálmason (1971), 4.0-5.0 km by MacKenzie et al. (1982) and 5.0-6.0 km by Staples et al. (1997). However, the main difference between the East Iceland crust compared to other parts of the crust in Iceland as observed by surface waves, is the slow seismic velocity of the lower crust. Only the lower crust of the CNS province has similarly low values. The lower crust of the $\mathrm{E}$ and $\mathrm{CNS}$ provinces is on average 
3 per cent slower than the velocity of the lower crust in the SIL model. Unsurprisingly, for the Central Iceland path, but surprisingly for the 8-15 Ma old East Iceland, as the velocity of the crust is expected to increase with age, possibly due to the cooling and hydrothermal filling of pores. Instead of interpreting anomalous slow lower crust in East Iceland, the structure can also be interpreted as combination of double thick upper-middle crust compared to the 5.0-km-thick upper-middle crustal average of Iceland (Flóvenz 1980) and slower lower crust.

The thicker upper-middle crust of East Iceland is suggested to be the result of eastward ridge jumps of the rift system (Saemundsson, 1980), where the upper-middle crust gets reburied with large amounts of new extrusives, causing a major age unconformity. One such unconformity is observed on the surface in East Iceland (Fig. 1, Jóhannesson \& Saemundsson 1998), with $\sim 1.5 \mathrm{~km}$ erosion of the older strata (Sæmundsson, private communication, 2006). In the East province number of acid extrusives have been observed, possibly indicating higher remelting of the crust. The relatively low velocity of the lower crust of East Iceland might also be explained by a higher proportion of extrusive originated material in the lower crust as interpreted earlier by Smallwood et al. (1998). Another explanation is a buried continental fragment (Bjarnason 2003; Foulger 2006). For further discussion, see Section 5.

\subsection{Anisotropy in the crust}

The surface waves show a large anisotropic signal in the crust. The anisotropy is here defined as $\left(\frac{S H-S V}{S V}\right) \times 100$ per cent. Due to incomplete azimuthal coverage, all anisotropy values quoted here refer to apparent anisotropy in a particular path direction, which may or may not be a good measure of total anisotropy. Prior to this study others have observed (i) crustal anisotropy with a horizontal fast direction in the upper crust (Menke et al. 1994; Crampin et al. 2002) or (ii) no or only a minor component of horizontal fast direction observed with receiver functions, that average the whole crust (Du \& Foulger 1999; Schlindwein 2001). Menke et al. (1994) interpreted an upper crustal anisotropy as being caused by fractures with dominant direction along the general strike of the rift in Iceland.

In this study, the largest anisotropic signal within the crust is observed in the top $2-3 \mathrm{~km}$ of the crust in the rift zones and the WF profile in the WF. The average anisotropy in the top $2 \mathrm{~km}$ surface layer is -9 per cent in the rift zones and -15 per cent under WF (Figs 4a, c and e). These anisotropies are interpreted to be caused by vertical fractures associated with the current rifting, aligned in the strike of the rift and extending to $\sim 2 \mathrm{~km}$ depth. The high shallow anisotropy under WF is harder to interpret. As mentioned before, there is a considerable uncertainty in the high frequency end along this path, making the derived shallow structure less certain.

One of the unexpected findings of this study is a layer with positive anisotropy, with the strongest signal under the rift zones surveyed, the West, North and Central Volcanic Zones (Figs 4c and e). The onset is in the midcrust, at 3-5 $\mathrm{km}$ depth, and extends $5-8 \mathrm{~km}$ into the lower crust. In this layer the $S H$ wave is on average 4 per cent faster than the $S V$ wave, with maximum anisotropy of +6 per cent. Every percent difference, is significant when looked at on this larger horizontal averaging scale. In this depth range between $\sim 5$ and $15 \mathrm{~km}$, the $S H$ structure is similar to what has previously been determined by a number of refraction experiments, but the $S V$ structure is unexpectedly slow.

Our favoured hypothesis is that this signal is due to a horizontal layer cake of stiff and soft layers. The Love waves and the refracted body waves are sensitive to stiff layers, as the Rayleigh waves are to soft layers. Lateral extension of these layers needs to be of the order of $20 \mathrm{~km}$. The thickness of these layers is unconstrained, but it is likely that the softer layers are thinner than the stiffer ones in line with refraction results, which do not see the softer layers. A less likely hypothesis is that the anisotropy is caused by an alignment of crystal fabric, with the average horizontal fast crystallographic axes striking $40-90^{\circ}$ to the direction of the rift system. It is both because a basaltic crust has less amount of anisotropic crystals, and such an alignment would 'freeze' in the crustal rocks and should be observed outside the rift zones, as a general feature of Icelandic crust. That is, however not the case. An obvious hypothesis would be to associate the softer horizontal layers with new subsurface horizontal volcanic intrusions. As they drift and cool outside of the volcanic zones, the stiffness will increase to the level of the rest of the rock mass, and the signal disappear. This is generally observed, except in the western part of the WF (Fig. 4a), which undermines this as a general hypothesis. An implication of such a hypothesis would be that a significant part of the crust is produced in the mid- and lower crust along the whole rift zone, in contrast with the shallow magma chamber model, but in agreement with the crustal accretion model of Schmeling \& Marquart (2008).

Other parts of the crust are also anisotropic, but none in such a systematic way as this mentioned layer. It can be said that the western part of WF, appears like an exaggerated anisotropic structure of the active rift zones, although it may be of another origin. The signal in the dispersion curves (inflection) that is causing the high $S V$ velocity body in the lower crust between 10 and $18 \mathrm{~km}$ under WF (Fig. 3a), was also observed by Du \& Foulger (1999; Fig. 9 there). Schlindwein (2006) observed similarily a high velocity between $\sim 10$ and $25 \mathrm{~km}$ depth and velocity inversion under $\sim 25 \mathrm{~km}$ depth from receiver functions of events with a northerly azimuth.

A layered crustal structure, with steeply tilting layers of $\sim 45^{\circ}$, will appear isotropic for surface waves. It is possible that the observed isotropy of the crust in East Iceland, could be partly due to steeply tilting layers as observed by Smallwood et al. (1998). Compared to other provinces, which all have a significantly anisotropic character, the East Iceland crust is anomalously well behaved in respect to its isotropic character.

\section{SUBCRUSTAL $V p / V s-\mathrm{RATIO}$ AND TEMPERATURE ESTIMATES}

In a number of refraction experiments in Iceland an apparent $P$ wave velocity of $7.8 \pm 0.2 \mathrm{~km} \mathrm{~s}^{-1}$ ( $S D=$ standard deviation) has been measured at 24-30 km depth (Gebrande et al. 1980; Bjarnason et al. 1993; Menke et al. 1998). These measurements were all in the vicinity of volcanic zones or under Central Iceland. Assuming this to be a low Pn velocity in the top of the mantle lid, and using the average surface wave velocity derived from $S V$ and $S H$ velocities of $4.08 \pm 0.02 \mathrm{~km} \mathrm{~s}^{-1}$ (SEM = standard error of the mean) throughout Iceland at the BCM, gives a ratio $V_{p} / V_{s}=1.91 \pm 0.03(S E M)$. The ratio is $1.88 \pm 0.04(S E M)$ when compared with the average $S H$ velocity alone. Allen et al. (2002a) inferred a similar high ratio of 1.92 at $35 \mathrm{~km}$ depth, but Menke et al. (1998) a lower ratio, $1.86 \pm 0.04(S D)$ at the BCM. It should, however, be noted that the inferred ratio of about 1.90 is probably an upper limit, because as discussed in Section 2, it is likely that the inversion underestimates the shallowest mantle-lid $S$-wave velocity.

A $V_{p} / V_{s}$-ratio of 1.90 is about 6 per cent higher than the standard $V_{p 0} / V_{s 0}$-ratio of 1.792 at these depths in the mantle (e.g. ak135 model of Kennett et al. 1995). Such an increase may indicate higher 
Table 2. Possible temperatures and melt parameters to explain the observed $V_{p} / V_{s}$-ratios at $30 \mathrm{~km} \mathrm{depth}$.

\begin{tabular}{|c|c|c|c|c|c|c|c|c|c|}
\hline$D$ & $\phi_{r}$ & Ref. lithosphere & Water & $a_{1}\left(K^{-1}\right)$ & $a_{2}\left(K^{-2}\right)$ & $a_{3}$ & $a_{4}$ & $T\left({ }^{\circ} \mathrm{C}\right)$ & $T-T_{\text {pot-corr }}(\mathrm{K})$ \\
\hline 0.20 & 1 per cent & $20 \mathrm{Ma}\left(1018^{\circ} \mathrm{C}\right)$ & Dry & $1.18 \mathrm{E}-05$ & $1,03 \mathrm{E}-07$ & 0.81 & $6,00 \mathrm{E}-03$ & 1631 & 282 \\
\hline 0.30 & 1 per cent & $"$ & $"$ & $"$ & $"$ & $"$ & $7.20 \mathrm{E}-03$ & 1621 & 313 \\
\hline$"$ & 3 per cent & $"$ & $"$ & ” & ” & $"$ & $"$ & 1490 & 182 \\
\hline$"$ & 2 per cent & $60 \mathrm{Ma}\left(531^{\circ} \mathrm{C}\right)$ & $"$ & $"$ & $"$ & $"$ & $"$ & 1461 & 153 \\
\hline 0.20 & 3 per cent & $"$ & $"$ & ” & $"$ & $"$ & $6,00 \mathrm{E}-03$ & 1374 & 25 \\
\hline 0.30 & 3 per cent & $"$ & $"$ & $"$ & $"$ & $"$ & $7.20 \mathrm{E}-03$ & 1357 & 49 \\
\hline$"$ & 1 per cent & $20 \mathrm{Ma}\left(1018^{\circ} \mathrm{C}\right)$ & $\mathrm{M}=10$ & $2.21 \mathrm{E}-05$ & $1.59 \mathrm{E}-07$ & $"$ & $"$ & 1483 & 175 \\
\hline$"$ & 3 per cent & " & $"$ & " & , & $"$ & $"$ & 1378 & 70 \\
\hline
\end{tabular}

than normal temperatures, the presence of melt or of water, or a higher melt depletion of mantle rock. The effect of water may be disregarded, because upon melting within the Iceland's asthenosphere, the water goes into the melt phase and the mantle rock matrix may be regarded as dehydrated. The temperature, the amount of melt and the melt depletion responsible for 6 per cent $V_{p} / V_{s}$-ratio increase can be estimated: Kreutzmann et al. (2004) calculated the anelastic and anharmonic effects due to an anomalous temperature $\Delta T$ with respect to the normal temperature of a 20 Ma reference oceanic lithosphere on the $V_{p}$ and $V_{s}$ velocities for peridotite as a function of depth. As also discussed in that paper, the presence of a melt with melt fraction $\phi_{r}$ distributed in pockets and channels along grain edges also reduces $V_{s}$ and $V_{p}$ velocities. Following Karato \& Jung (1998) Kreutzmann et al. (2004) accounted also for the effect of water by introducing a factor $M$ which increases the mobility of dislocations. The effect of melt depletion D (removed fraction of melt) on the $V_{p} / V_{s}$-ratio can be estimated for a peridotite at $30 \mathrm{~km}$ depth using the experimental data given by Schutt \& Lesher (2006). Combining these effects for a depth of $30 \mathrm{~km}$, we arrive at an approximate relation

$\frac{V_{p}}{V_{s}}=\frac{V_{p 0}}{V_{s 0}}\left(1+a_{1} \Delta T+a_{2} \Delta T^{2}+a_{3} \phi_{r}+a_{4} D\right)$

for which the parameters $a_{1}$ and $a_{2}$ are determined by quadratic regression of the temperature dependence of $V_{p} / V_{s}$-ratio as derived by Kreutzmann et al. (2004), $a_{3}$ is the same value as used by Kreutzmann et al. (2004) and $a_{4}$ is determined from analysing Figs 8 and 9 of Schutt \& Lesher (2006). Given various assumptions on $\mathrm{D}$, the retained melt fraction $\phi_{r}$ (approximately 1-3 per cent, see discussion in Schmeling 2006), dislocation mobility factor $M$ due to water, and two reference temperature profiles of oceanic lithosphere of different ages (for which we assume the reference $V_{p 0} / V_{s 0}$ ratio of 1.79), the observed anomalous $V_{p} / V_{s}$-ratio of 6 per cent at $30 \mathrm{~km}$ depth can be explained by various anomalous or total temperatures at that depth (Table 2). Here, $T_{\text {pot-corr }}$ is the reference potential temperature which produces normal oceanic crust (Ruedas et al. 2004), corrected to a depth of $30 \mathrm{~km}$ and for the effect of latent heat due to melting (uncorrected: $1420^{\circ} \mathrm{C}$ ).

The M-value of 10 for wet mantle corresponds to a small water content (about $20 \mathrm{ppm} \mathrm{H} / \mathrm{Si}$ ). A higher water content is unlikely due to dehydration at melting. Table 2 shows the sensitivity of temperature at $30 \mathrm{~km}$ depth and the anomalous temperature compared to a normal oceanic asthenosphere at the same depth, corrected for the effect of latent heat due to melting ( $D=0.2$ or 0.3 , respectively). From the table above we favour cases with a 60 Ma reference lithosphere because it is more likely that the global ak135 seismic model is more representative of older lithosphere. Taking the higher depletion value representative of extensive volcanism and a retained melt fraction of 2-3 per cent we predict a temperature at $30 \mathrm{~km}$ of about $1350-1460{ }^{\circ} \mathrm{C}$ or an anomalous temperature $T-T_{\text {pot-corr }}=$
$50-150 \mathrm{~K}$. The lower values of the above temperature range corresponding to 3 per cent melt agrees well with the excess temperature estimate of the Iceland plume of $135 \mathrm{~K}$ at $200 \mathrm{~km}$ depth, based on dynamic models constrained by seismic anomalies and crust generation rates (Kreutzmann et al. 2004): Accounting for adiabatic cooling and heat loss due to latent heat absorbtion when melting, their plume model predicts $1386{ }^{\circ} \mathrm{C}$ at a depth of $30 \mathrm{~km}$. It should, however, be noted, that other estimates of excess mantle temperatures beneath Iceland vary between $0 \mathrm{~K}$ (explaining the observed seismic velocity anomaly by water and/or small amounts of melt) and $300 \mathrm{~K}$ (explaining regional tomography, see reviews by Foulger et al. 2001; Vinnik et al. 2005; Ruedas et al. 2007). Thus, the above estimate based on new observation of the anomalous $V_{p} / V_{s^{-}}$ ratio strengthens the intermediate to high range estimates. If, on the other hand, the amount of water at $30 \mathrm{~km}$ depth is larger $(M>10)$, for example, due to incomplete dehydration by melting or due to partly solidification of wet melt, the temperature prediction would have to be shifted towards smaller values. It should also be noted, that if the $V_{p} / V_{s}$-anomaly is smaller than 6 per cent $\left(V_{p} / V_{s}\right.$ of 1.90 being an upper limit), the above estimates of excess temperature and melt fractions would have to be reduced accordingly.

It is interesting to compare these temperatures with the temperature of basaltic magma of $1100-1200{ }^{\circ} \mathrm{C}$ as it reaches the surface in Iceland, having remained for some time in the crust or close to the BCM (Steinthórsson, private communication, 2006). Picrite basalt on the Reykjanes peninsula is thought to have erupted at even higher temperature between 1280 and $1320{ }^{\circ} \mathrm{C}$, originating as partial melt (primitive magma) from $\sim 85 \mathrm{~km}$ depth according to Maaløe \& Jakobsson (1980). They measured picrite melt at phase (eutectic) equilibrium at $1400{ }^{\circ} \mathrm{C}$ and $10 \mathrm{kbar}$ pressure ( $\sim 33 \mathrm{~km}$ depth). This may possibly be a higher temperature than of the solid mantle at that depth, as for example, indicated by pyrolite batch melting experiments (Green \& Falloon 1998), where mid-ocean ridge picrites are produced under pressure, corresponding to $\sim 40-65 \mathrm{~km}$ depths and temperatures $1345-1450{ }^{\circ} \mathrm{C}$. Thus the eruptive temperatures $1200-1300^{\circ} \mathrm{C}$ can be regarded as a lower bound and the $1400{ }^{\circ} \mathrm{C}$ as the upper bound temperature at depth of $\sim 30 \mathrm{~km}$. Based on this comparison our temperature estimate of $1400 \pm 50^{\circ} \mathrm{C}$ is consistent with the upper bound of the petrological estimates, or in other words, the lower of our temperature estimates $\left(1350{ }^{\circ} \mathrm{C}\right)$ fits well with the petrological constraints. We thus conclude that the observed $V_{p} / V_{s}$-anomaly under Central Iceland and the volcanic zones, predicts the higher of the partial melt concentrations (2-3 per cent), a depletion of about 0.30 and temperature close to the solidus of depleted mantle at $\sim 30 \mathrm{~km}$ depth (Langmuir et al. 1992).

\section{LITHOSPHERE}

One of the purposes of this research is to the map of the lithosphere thickness or the depth to the LAB. Two receiver function studies 
using the ICEMELT and HOTSPOT data sets have proposed quite surprising results of an almost constant $80-\mathrm{km}$-thick lithosphere under the whole of Iceland, the same thickness as, for example, under large parts of continental Greenland (Vinnik et al. 2005; Kumar et al. 2005). Older studies, were unable to probe to sufficient depth, in order to meaningfully distinguish between the lithosphere and asthenosphere. This study defines the lithosphere-asthenosphere boundary or transition by either the depth at which a large scale and consistent inversion (decrease) with depth is observed in the $S V$-models, or by the depth within the mantle or even within the crust at which the $S V$ velocities show significantly low, anomalous values. It is reasonable to take $S V$ rather than $S H$ for the definition of the LAB, because $S V$ corresponds to deformation controlled by horizontally stratified rheology or elasticity, while $S H$ corresponds to toroidal deformation insensitive to stratification. The $S V$ structure maps the occurrence of possible weak decoupling horizontal layers that the plates can glide along, more effectively than the $\mathrm{SH}$ structure.

The extension of the asthenosphere up into the crust seems to be demonstrable in the Central and North Iceland's Volcanic Zones (CNS, Figs 4e and 7e). This is in agreement with interpretations of GPS, gravity and uplift rate data which find a rheological asthenosphere at a depth below 10-30 km (Sigmundsson 1991; Hofton \& Foulger 1996a,b; Pollitz \& Sacks 1996; Fleming et al. 2007). This is also in general agreement with Kaban et al. (2002) who derived from gravity modelling the thinnest lithosphere of Iceland, 20-30 km thick (depth to $1200^{\circ} \mathrm{C}$ isotherm), along the Northern Volcanic Zone, under the north third part of the CNS profile. A lithosphere being thinner than the crust may not be very common elsewhere, but this finding does not contradict conventional definitions: While the seismic BCM is related to a compositional boundary, the lithosphere-asthenosphere boundary (transition) is a rheological boundary, and both these boundaries affect seismic velocities in their own characteristic ways. In the CNS province the $S V$ structure lacks a clear mantle lid, but at $20 \mathrm{~km}$ depth (in the crust) the velocity gradient drops from a $1.7 \times 10^{-2} \mathrm{~s}^{-1}$ regular lower crustal gradient to a mantle gradient value $5 \times 10^{-3} \mathrm{~s}^{-1}$. Significantly different starting models $\left(\right.$ RMSE $=0.09 \mathrm{~km} \mathrm{~s}^{-1}$ ) do not perturb the depth of the LAB more than within the given error bars.

The following picture of the lithosphere thickness in Iceland emerges: The CNS province, where the crust is $29 \mathrm{~km}$ thick, has a $20 \pm 2 \mathrm{~km}$ thick (SV) lithosphere (Fig. 7e). As discussed in the previous paragraph the asthenosphere extends up into the crust and no mantle part (mantle lid) belongs to the lithosphere. Under the West Volcanic Zone (W) and West-Central Iceland (CEW), the lithosphere is $30-35 \pm 5 \mathrm{~km}$ thick ( $S V$ in Figs $7 \mathrm{c}$ and d). However, as mentioned before it is questionable if mantle with -7.3 and -9.0 per cent perturbations from PREM's $S V$ and $S H$ mantle lid velocities, can be called a mantle lid. That interpretation would reduce the lithosphere in the greater central Iceland zone (i.e. between and including the main active rift zones of Iceland) to approximately $20 \mathrm{~km}$ thickness. The 40-km-deep seismic discontinuity under Central Iceland (Darbyshire et al. 1998; Du \& Foulger 2001) is then either from the lithosphere-asthenosphere boundary or a reflector within the mantle asthenosphere. The thickness increases to 55-65 $\pm 5 \mathrm{~km}$ (SV) under the WF and Northwest Iceland (Figs 7a and b). Shear wave velocities reach a normal mantle lid velocities of $\sim 4.5 \mathrm{~km} \mathrm{~s}^{-1}$ under the WF at 35-40 km depth. Thickening of the lithosphere by an amount of $\sim 30 \mathrm{~km}$ in $15 \mathrm{Ma}$ due to plate cooling on the west side of Iceland is a reasonable assumption. For reference a 20 Ma Pacific Ocean lithosphere is $30-40 \mathrm{~km}$ thick (Turcotte \&
Schubert 1982; Nishimura \& Forsyth 1989), so the thicker lithosphere under the WF is probably due to a thicker crust, with possibly higher effective cooling in its extrusive part.

Another mystery appears: East Iceland has a minimum $100 \pm$ $20 \mathrm{~km}$ thick $(S V)$ lithosphere (Fig. 7f). Its maximum thickness is not constrained because the $S V$ models do not have velocity inversion within their well resolved depth (except the -95 per cent confidence model). East Iceland is anomalous, within otherwise anomalous Iceland. Its lithosphere thickness resembles a continental thickness or standard model of oceanic lithosphere $200 \pm 100$ Ma year old (thermal age, e.g. Turcotte \& Schubert 1982). As in the WF, here the shear wave velocities reach more normal mantle lid velocities of $\sim 4.4 \mathrm{~km} \mathrm{~s}^{-1}$, but deeper than in the WF, at $60 \mathrm{~km}$ depth. The upper bound of oceanic lithospheric age in this part of the Atlantic ocean is under $80 \mathrm{Ma}$. Could it be that this large lithospheric thickness is an apparent effect of anisotropy? The NNW-SSE fast velocity direction under East Iceland observed with split SKS shear waves (Bjarnason et al. 2002), will speed up the Love waves, but not Rayleigh waves at the same time as is observed. Seismic body wave tomography has previously seen evidence for a seismically faster lithosphere in East Iceland than the WF (Wolfe et al. 1997) and Foulger et al. (2001) saw a slightly seismically faster East Iceland shelf compared to WF shelf, which can be interpreted as a thicker lithosphere.

How does the lithosphere in Iceland compare with the lithosphere in neighbouring regions? Evans \& Sacks $(1979,1980)$ measured lithosphere thicknesses to the north and south of Iceland with a similar method as in this work. They found a 25-30-km-thick lithosphere on the Reykjanes ridge crest, $200 \mathrm{~km}$ southwest of Iceland, but with higher lid velocity than is seen under Central Iceland. The low velocities reflect possibly higher temperature and larger amount of partial melt under the greater Central Iceland region than under the Reykjanes ridge. Between Iceland and the Charlie-Gibbs fracture zone along on average $40 \mathrm{Ma}$ old ocean floor, they found a 70-km-thick lithosphere. To the north of Iceland in the Iceland Plateau, $24 \mathrm{Ma}$ old lithosphere is $45 \mathrm{~km}$ thick.

The thicker lithosphere of East Iceland compared to neighbouring regions in the North Atlantic and compared to the WF needs to be explained. Is there an age unconformity between the surface geology (upper crust) and the mantle, under East Iceland? Such an age unconformity could either be in the form of (1) an old (>25 Ma) oceanic mantle or (2) a buried, rather cold, continental fragment (Bjarnason 2003; Foulger 2006) with a composition unconformity (i.e. continental versus oceanic basalt), that may even extend up into the lower crust, in reference to the slow East Iceland lower crust. Staples et al. (1997) infer a considerable velocity jump (>10 per cent) over the BCM beneath the Tertiary parts of East Iceland. That may suggest a different nature of the Moho there compared to many other parts of Iceland, but without direct observation of Pn velocity it remains uncertain. Based on gravity data Fedorova et al. (2005) have modelled crustal thickening along the SE Iceland shelf and interpreted this as continental splinter of similar origin as the Jan Mayen ridge.

One observation does not agree well with the hypothesis of continental lower crust in East Iceland: It was first noted by Moorbath \& Walker (1965), that geochemistry does not reveal any significant continental signature in Iceland. That has been confirmed by many authors but with exceptions (e.g. Prestvik et al. 2001). It may also seem odd that heat-flow is comparable in the WF and East Iceland (Flóvenz \& Sæmundsson 1993), that is, two regions with different lithospheric thickness and perhaps also different lithospheric age. Similar order of heat-flow in regions of different lithospheric 

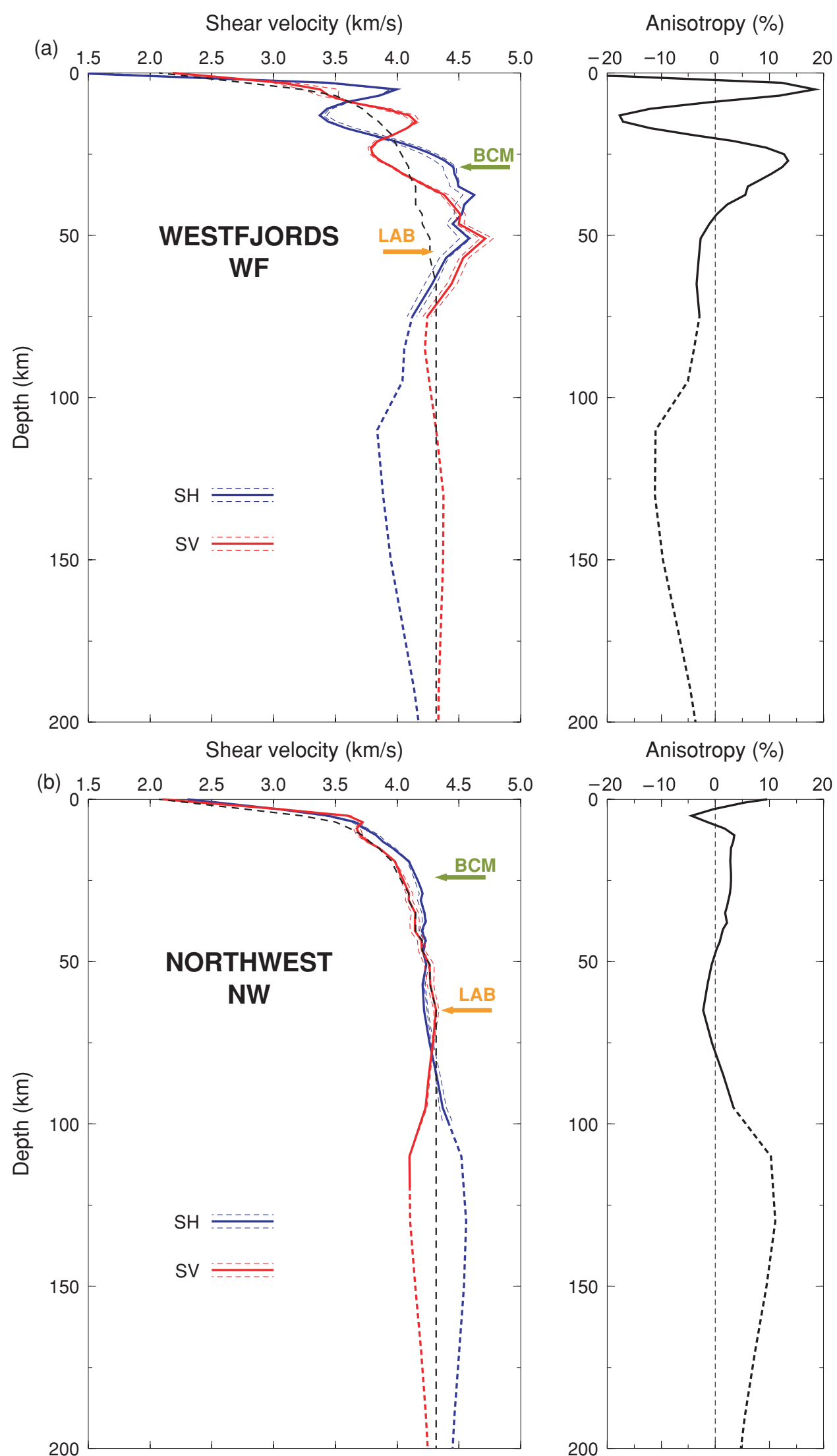

Figure 7. Same velocity models as in Fig. 4 down to $200 \mathrm{~km}$ depth, with the starting model $8 \mathrm{f}$ (stippled black line) as a reference. Below the depth corresponding to the half wavelength of the longest period, the velocity models are plotted as stippled line only. Above the half wavelength depth, the surface waves have a reasonable vertical resolution. 

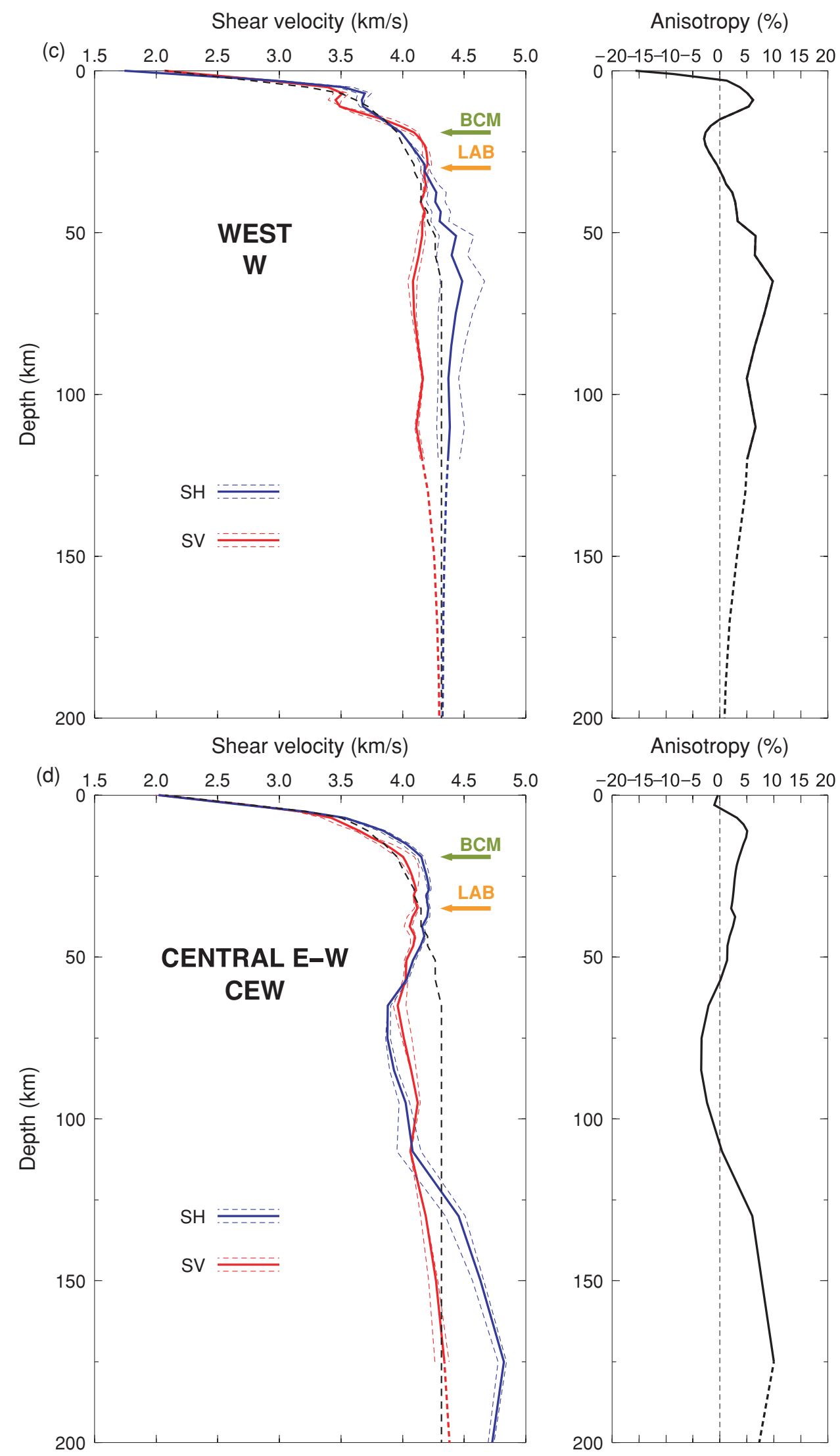

Figure 7. (Continued.) 

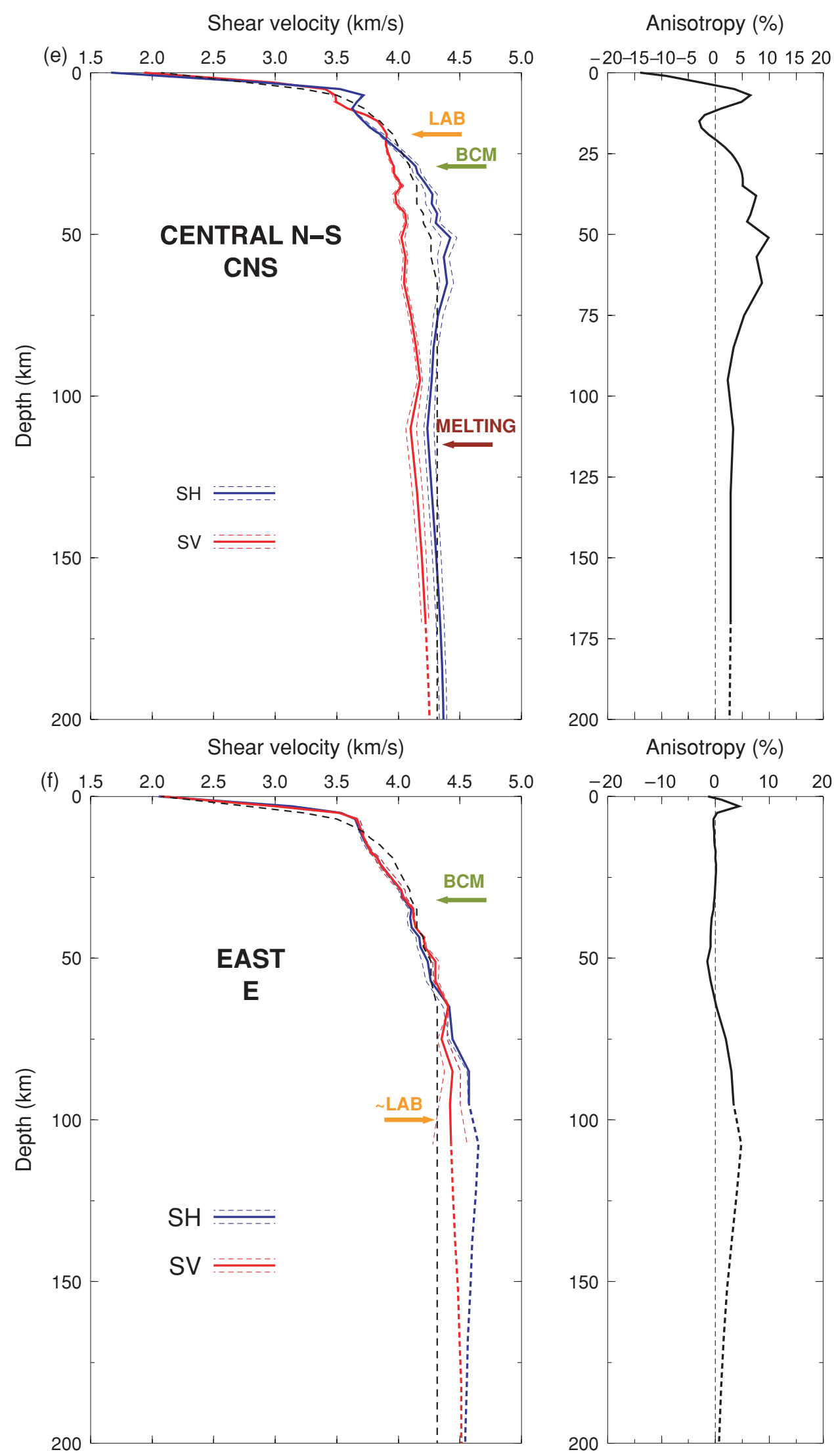

Figure 7. (Continued.) 
thickness may be explained by an enhanced advective heat transport due to vertical (dykes) and horizontal (sills and sideway extrusions) magma transport compared to purely conductive cooling of a plate. In other words, even a slightly higher shallow crust accretion rate in the east may outpace the lower conductive heat flow associated with the thicker lithosphere there. The rather recent (last ice-age) higher errosion of the East Iceland pile may also be a factor in the comparable near-surface heatflow with the WF.

A third hypothesis (3) does not assume a large (>10 Ma) age unconformity between the crust and the mantle. It assumes that there is at least $50-\mathrm{km}$-thick crust under East Iceland on top of a similar aged mantle lid as under the WF. This idea is not supported by many data, except that the surface waves see mantle lid velocities of $\geq 4.3 \mathrm{~km} \mathrm{~s}^{-1}$ only at depths greater than $\sim 50 \mathrm{~km}$. A $50-\mathrm{km}$-thick crust would contradict previous crustal thickness measurements of 35 km (Staples et al. 1997; Smallwood et al. 1998), but a weakness of them is that a $P n$ velocity has yet to be observed under East Iceland, and hence a clear identification of a BCM has not been possible. At the moment, the first hypothesis fits best: Most probably an age unconformity exists between the crust and mantle under East Iceland. The offshore 33-43 Ma old (magnetic anomalies 13-20) oceanic mantle south of Southeast Iceland (Nunns et al. 1983), extends under East Iceland and the East Iceland shelf. On top of this older thicker mantle lid, lies the thickest part of the Icelandic crust. Combined they form a thick lithosphere.

An anomalously thick East Iceland crust can be explained by the interaction of the eastward migrating Mid-Atlantic ridge, several ridge jumps within the past $40 \mathrm{Ma}$ and the varying position of the Iceland plume head. In a dynamic, plume-ridge model of the North Atlantic, Mihalffy et al. (2008) investigated the thermal and dynamical interaction of a thermal plume which is overridden by the North Atlantic ridge. The migrating ridge was modelled as a time dependent kinematic boundary condition according to reconstructed plate motions of the past $60 \mathrm{Ma}$. These plate motions include several ridge jumps, that is, ridge jumps were included as constraints on the models. These boundary conditions were applied to a fully dynamical convection model into which a thermal plume has been injected at $660 \mathrm{~km}$ depth. Once the ridge approaches the plume head, it is attracted by the ridge and deformed in a way as to follow the migrating ridge for a few tens Ma.

As an example of this kind of model, Fig. 8(a) shows the modelled plume at the present time with its head being strongly deformed, the stem tilting downward to the SSW (Mihalffy et al. 2004, and Mihallfy, unpublished data). If the plume source is fixed within the upper part of the lower mantle, the interaction with the ridge may lead to strongly asymmetric plume head tracks on either side of the North Atlantic lithosphere plates. This is shown in Fig. 8(b) (Mihalffy et al. 2008), where the coloured regions depict those parts of the plates, which have been exposed to plume magmatism at the time of their spreading history. Clearly, the magmatic plume head material is rapidly transported away from the plume centre towards the west on the American side, while it piles up on the eastern side. This accumulation on the eastern side is partly a consequence of repeated ridge jumps towards the west (at $32 \mathrm{Ma}$ ) and the east (between 20 and $0 \mathrm{Ma}$, Hardarson et al. 1997), since they always occurred towards the position of the plume head. Piling up of magmatic material of different age at the eastern side requires that the width of the accretional rift zones and the distance between subsequent ridge jumps are of similar order. Inspection of the geological map of Iceland shows that this is almost the case $(50 \mathrm{~km}$ versus 50-100 km, respectively).

\section{ASTHENOSPHERE}

The asthenosphere is a low velocity zone in the mantle. As described before, the onset of the lithosphere-asthenosphere transition zone is unconstrained but is below $100 \pm 20 \mathrm{~km}(S V)$ depth under East Iceland, is constrained at $20 \pm 2 \mathrm{~km}$ to $35 \pm 5 \mathrm{~km}(S V)$ under Central Iceland, and at 55-65 $\pm 5 \mathrm{~km}$ depth $(S V)$ under Northwest Iceland and the WF. The $S V$ velocity is at minimum within the asthenosphere under Central Iceland in the depth range 40-80 km (Figs 7c-e). This zone is positioned between the West, East and North Volcanic Zones, that is, the greater Central Iceland region. Its north-south extend is unconstrained, but is $\sim 200 \mathrm{~km}$ in diameter in the east-west direction. It can be interpreted as a continuation of the plume like low velocity zone to shallower levels than has clearly been constrained before (Wolfe et al. 1997; Foulger et al. 2001; Allen et al. 2002b; Du \& Foulger 2004). The maximum lateral anomaly of the $S V$ velocities is $9-13$ per cent between Central Iceland's low velocity and the mantle lid velocities of the Iceland's oldest provinces in the East- and WF. This is a large variation. Foulger et al. (2001) and Allen et al. (2002b) have found lateral shear velocity anomaly in this depth range in the order of 4 per cent across Iceland. A likely consequence of this asymmetric shape of the lithosphere-asthenosphere transition zone, is asymmetric mantle flow and probably a hotter mantle in the west compared to the east. This asymmetric shape is in agreement with the asymmetric plume head (Fig. 8a) and hotspot track (Fig. 8b) based on the dynamic model of Mihalffy et al. (2008).

At greater depth a common feature appears in the asthenosphere landscape under the greater central region and Northwest Iceland. It is in the form of a minimum in the shear velocity at $110 \mathrm{~km}$ depth. Above this minimum in central Iceland, there is an increase in the $S V$ velocity with higher velocity at $90 \mathrm{~km}$ depth, but more shallowly, the velocity falls again, giving the appearance of a double LVZ in the asthenosphere ( $S V$ in W, CEW and CNS provinces, Figs 7ce). Kreutzmann et al. (2004) have calculated the onset of melting at $110-120 \mathrm{~km}$ under Central Iceland (Fig. 7e), based on surface wave velocity anomaly in comparison with the sub oceanic Iceland Plateau. Perhaps the LAB at $80 \mathrm{~km}$ depth determined by Vinnik et al. (2005) and Kumar et al. (2005) is due to seismic conversions in this region between the double LVZ.

Kreutzmann et al. (2004) explain the increase in velocity above the deeper LVZ to be due to cooling of the mantle by consumption of latent heat as it starts to melt. At $\sim 100 \mathrm{~km}$ depth, equally low $S V$ velocity, as under Central Iceland, are observed under Northwest Iceland, indicating a flow of the plume head in that direction. It is likely that this minimum extends under all of the western half of Iceland. It remains to be constrained if a narrow zone $(\sim 20 \mathrm{~km}$ thick) of the mantle could be partially molten at $100 \mathrm{~km}$ depth under Northwest Iceland, an area without any active volcanism. However, neovolcanism does exist up to $170 \mathrm{~km}$ west of the West Volcanic Zone in a linear trend along the Snaefellsnes peninsula (Fig. 2).

Based on the results of Kreutzmann et al. (2004) it can be inferred that the whole mantle in the greater central region is partially molten from the onset of melting at 110-120 km depth to $\sim 40 \mathrm{~km}$ depth, or in a $70-80 \mathrm{~km}$ thick melting region with a $200 \mathrm{~km}$ diameter. They assume that there is only a low 1 per cent partial melt on average in the melting zone, but as discussed before the partial melt probably increases towards shallower parts of the mantle. At the east edge of the central region, the LVZ extends even shallower, with partially molten mantle up to the BCM at $29 \mathrm{~km}$ depth. The calculations of Kreutzmann et al. (2004) do not apply to the crust, 

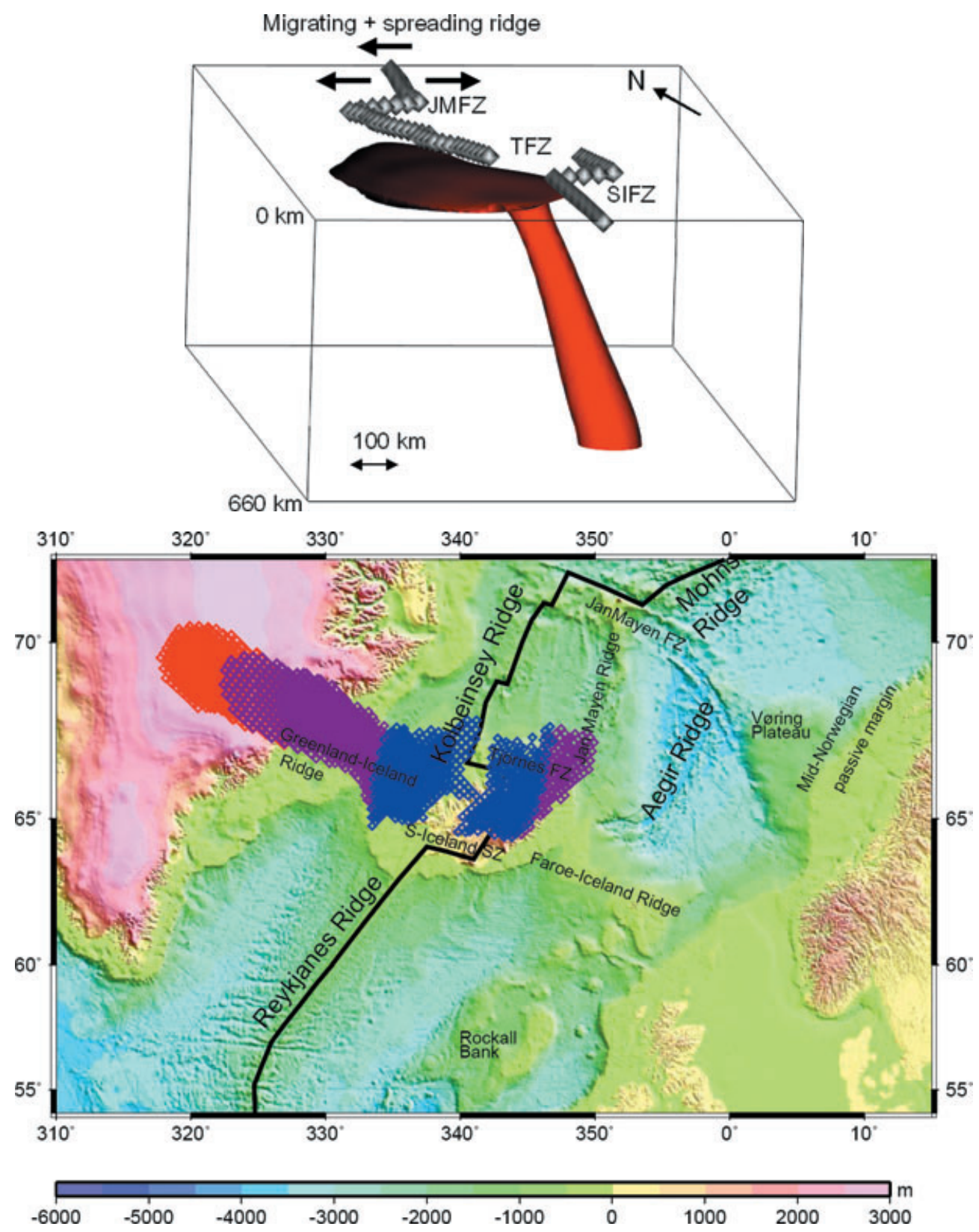

Figure 8. (a) Time-dependent convection model of plume-ridge interaction by Mihalffy et al. (2004) and P. Mihalffy (unpubl. data). The plume is visualized as the surface of a constant anomalous temperature. The snapshot shown is taken at the present time as the plume is overridden by the spreading ridge towards the NW. The ridge is indicated as chain of diamonds and fracture zones labeled JMFZ (Jan Mayen), TFZ (Tjörnes) and SIFZ (South Iceland). For further explanations, see text. (b) Hotspot track of a successful plume-ridge interaction model by Mihalffy et al. (2008). The colours indicate those parts of the plates which have been exposed to plume magmatism at the times 0-20 Ma (blue), 20-40 Ma (purple) and 40-50 Ma (red) of their spreading history. With permission of Tectonophysics.

but by inference, due to the lower solidus of the crust, partial melt might extend somewhat further into the crust in the central-north rift.

\section{ANISOTROPY IN THE MANTLE LID AND THE ASTHENOSPHERE}

There is considerable anisotropy in the mantle under Iceland, which will be an important source for better understanding the state and dynamics of the mantle and the large scale plate tectonics in this part of the North Atlantic. Several authors have reported that there is a general environment of azimuthal anisotropy under Iceland (Bjarnason et al. 2002; Li \& Detrick 2003; Pilidou et al. 2005;
Xue \& Allen 2005). To constrain azimuthal anisotropy with surface waves, a good azimuthal coverage of paths is required. Even though azimuthal coverage is rather limited in this study, this is to some extent remedied by simultaneous analysis of Rayleigh and Love waves. However, there is more to anisotropy than azimuthal variation. Previous studies cannot, for example, constrain the mode of anisotropy called transverse isotropy (polarization anisotropy). A comprehensive view of anisotropy under Iceland will only be revealed with considerable future work.

When all these different observations are pieced together to try to understand the underlying anisotropic structure, not all the data fit together perfectly. Large variations of the 1-D anisotropy models 
across Iceland clearly show that it is a 3-D structure (Figs 7a-f). Bjarnason et al. (2002) and Xue \& Allen (2005) concluded from shear wave splitting measurements, which give a depth averaged anisotropy, that the horizontal fast directions do not have significant depth variation. They, however, clearly observed a lateral variation in the fast direction across Iceland, indicating 2-D structure. The surface waves of this work and the work of Li \& Detrick (2003), point to a significant vertical variation, although there may be one layer with the highest weight in the depth averaged anisotropy as seen by shear wave splitting. For example, the CEW province has two or three significant anisotropic layers in the 1-D anisotropic model (Fig. 7d).

In contrast to the PREM model the surface waves presented here show anisotropy that is relatively lower in magnitude in the mantle lid than in the asthenosphere. The PREM model has the highest anisotropy in the mantle lid, +4.0 per cent on average, decreasing to +3.0 per cent and +0.4 per cent at 100 and $200 \mathrm{~km}$ depths, respectively, in the asthenosphere (Fig. 5). In most parts of Iceland anisotropy is positive in the mantle lid, as in the PREM model, but both positive and negative in the asthenosphere. With the exception of the WF province, the magnitude of the average anisotropy in the mantle lid is relatively small $(< \pm 3$ per cent), but reaches up to +10 per cent and -4 per cent with a large volume extent in parts of the well resolved asthenosphere under Iceland (Figs 7a, $\mathrm{c}, \mathrm{d}$ and e). While interpreting the anisotropy of the mantle lid, it is also important to notice what is not observed. With positive or near zero anisotropy in the mantle lid along all paths, except in the $\mathrm{W}$ province, it is clear that there is not a horizontal fast direction in the plate spreading direction. The rather mild anisotropy in the mantle lid of Iceland is probably mainly of transverse isotropy mode, suggesting horizontal layered structure, though not with large impedance contrast between the layers due to the moderate anisotropy.

The two modes of observation, shear wave splitting, that have mapped the azimuthal anisotropy across Iceland, and surface waves, that map the location of the highest anisotropy in amplitude and volume in the asthenosphere, suggest that the dominant anisotropy causing the the azimuthal variation is lattice preferred orientation (LPO) of crystals, induced by differential shear in the ductile flowing asthenosphere.

In the depth range $\sim 30-65 \mathrm{~km}$, there is a high $5-7$ per cent average positive anisotropy with maximum value 10 per cent in the asthenosphere under the rift provinces $\mathrm{W}$ and CNS, that increases with depth (Figs 7c and e). In the CEW province the anisotropy is also positive in this depth range, but less in amplitude and decreases with depth, changing sign at $60 \mathrm{~km}$ depth (Fig. 7d). Transverse isotropy model would hardly fit in this depth range in all of these provinces, at least not a constant transverse isotropy, but neither does a common azimuthal model. The azimuthal model that fits best qualitatively has approximately north-south fast direction, although not exactly in the ridge parallel direction. It is in a reasonable agreement with Li \& Detrick (2003). This direction is deduced from the ratios of the $S H$ and $S V$ velocities and theoretical calculations of, for example, Maupin (1985) for azimuthal anisotropy. The high anisotropy observed under the ridge paths, compared to CEW that crosses only partly the ridge areas, is perhaps an indication of quite localized anisotropy in the rift environment even at this considerable depth. Li \& Detrick (2003) have hypothesized that ridge-parallel fast direction down to $50 \mathrm{~km}$ depth is due to combination of a ridge-parallel alignment of melt films and channeling of hot plume material along the ridge axis at greater depth. Laboratory measurements indicate that mantle flow direction may, however, be perpendicular to the anisotropy fast direction in melt ridge environment (Holtzman et al. 2003).

In the depth range $60-110 \mathrm{~km}$ the anisotropy of the CEW province supplies quite diagnostic observation. It is negative (Fig. 7d). When interpreted with the positive anisotropy of CNS and W, several models can be excluded. It excludes transverse isotropy and vertical cracks. Vertical cracks (e.g. melt sheets) or vertical layers would show low $\mathrm{SH}$ velocity in all three provinces. Similarly it excludes vertical LPO fast direction in greater Central Iceland, which would measure with low $\mathrm{SH}$ velocity in all three provinces. That leaves approximately ridge perpendicular fast direction (WNW-ESE) as the preferred model. It seems likely that a stronger factor in an ESE-WNW mantle flow is from a horizontal plume flow rather than a flow induced from the North American plate drag, because the effect of plate drag should extend to shallower depth. Below $110 \mathrm{~km}$ depth the CNS and CEW have a resolvable fast direction that is approximately between NW-SE and NNW-SSE directions, and the less well resolved anisotropy of the $\mathrm{W}$ province does also agree with this range of direction. The depth integrated shear wave splitting of Xue \& Allen (2005) in the greater central Iceland stations off the HOTSPOT network show mostly NW-SE fast directions or NE-SW null splitting direction. Bjarnason et al. (2002) predicted a deeper background upper mantle flow in the direction $\mathrm{N} 34^{\circ} \mathrm{W}$ under the Iceland region. Interestingly, Pilidou et al. (2005) measured a $\sim 1500 \mathrm{~km}$ wide anisotropic body in the asthenosphere extending from the central East Greenland coast through the Iceland region into South Central Europe with approximately the predicted fast direction of Bjarnason et al. (2002). Bjarnason et al. (2002) had sparse splitting observations in the Central Iceland region, but would predict a more northerly horizontal fast direction, due to differential shearing between the hypothesized background flow and the North American plate motion than observed by Xue \& Allen (2005). Analysis of Li \& Detrick (2003) does not penetrate to this deeper layer.

Several authors have noted that anisotropy induced by LPO can explain a theoretical +8 per cent maximum anisotropy in the case of perfect fast-axis distribution in the horizontal plane in pyrolite mantle material (Maupin \& Cara 1992; Ekström \& Dziewonski 1998; Debayle \& Kennett 2000). Even a somewaht higher anisotropy can be achieved with more unrealistic mantle model or alignment of the fast axes in a narrow azimuthal range. In about 15-km-thick zone in the depth range $50-75 \mathrm{~km}$ under the rift provinces CNS and $\mathrm{W}+8$ per cent anisotropy is reached although not significant at the 95 per cent confidence level in the $\mathrm{W}$ province. As it is hard to imagine near perfect fast-axis horizontal alignment for real Earth, we propose that this high positive anisotropy is a combination of LPO and horizontal melt saturated layers. The theoretical +8 per cent maximum anisotropy is also reached in the depth range of $150-175 \mathrm{~km}$ under the CEW province. The idea of a combination of melt and LPO does not apply there, because the 150-175 km range lies deeper than the melting zone of the mantle. However, at this greater depth, the velocity models are constrained by less data.

\section{CONCLUSIONS}

Rayleigh and Love wave data have been analysed and inverted for representative regions of Iceland. Using a change in the vertical seismic velocity gradient to define the BCM and other, more traditional, criteria to define the upper crust and the top of the asthenosphere, a new structural model of the Icelandic lithosphere and asthenosphere has been derived. These results include some unexpected new features and interpretations summarized in the following conclusions. 
(i) In contrast to previous models which proposed a crustal thickness of up to $40 \mathrm{~km}$, our results suggest a thinner crust in Central Iceland: approximately $19 \mathrm{~km}$ in west Central Iceland and $29 \mathrm{~km}$ along the east Central and the North Volcanic (rift) Zones.

(ii) A pronounced thickening of the crust away from the Central Volcanic Zone towards the northwest and east edge of the Iceland hotspot is observed. Interpreted dynamically, this thickening may be due to differential flow (squeezing-type) within the lower crust.

(iii) An approximately 8-km-thick mid-to-lower crustal anisotropy layer is found with $S V$ on average 4 per cent $<S H$ under the volcanic zones with onset at about $4 \mathrm{~km}$ depth. A similar anisotropy layer is found under the western most part of Northwest Iceland, but with higher average anisotropy. Our most favoured explanation of the observed anisotropy is a subhorizontal layer cake of stiff and soft layers, possibly a result of mid- to lower-crust accretion by subsurface subhorizontal volcanic intrusions.

(iv) Subcrustal $V_{p} / V_{s}$-ratios in Central Iceland at a depth of $30 \mathrm{~km}$ are about 6 per cent higher than for a global reference model (ak135). Accounting for a possible $V_{p} / V_{s}$-ratio dependence on temperature, melt fraction, depletion and water, a total temperature of about 1350 to $1460{ }^{\circ} \mathrm{C}$ and $2-3$ per cent melt fraction are predicted for that depth under Central Iceland and the volcanic rift zones.

(v) The upper-middle crust (extrusive and bitrusive) is thickest in Central Iceland $(8.4 \mathrm{~km})$. A pronounced E-W asymmetry in upper-middle crust thicknesses is found with only $3.7 \mathrm{~km}$ for the Westfjord region and $6.7 \mathrm{~km}$ for the similarly aged East Iceland. This asymmetry might be the result of subsequent eastward ridge jumps of the rift system.

(vi) Beneath East Iceland the crust and mantle shows a pronounced anomaly: the lower crust has an anomalously low velocity and/or the upper-middle crust has twice the thickness compared to Iceland's average. The lithosphere has a thickness of at least $100 \pm$ $20 \mathrm{~km}$. As this thickness is not compatible with a oceanic lithosphere of same crustal age, a hypothesis is favoured where there is an age unconformity between an anomalously thick crust and an older (33-43 Ma) mantle lid. The anomalously thick crust could be the result of repeated ridge jumps subsequently accumulating volcanic material on top of the older mantle lid.

(vii) Beneath Central Iceland and towards Northwest and West Iceland a deep low velocity zone (LVZ) is observed between 100 and $125 \mathrm{~km}$ depth. A second shallower LVZ is observed between Central and West Iceland at the depths of 30-80 km. These structures may be explained by a partially molten asymmetric plume head.

(viii) Anisotropy in the asthenosphere is a 3-D structure and is generally larger than in the mantle lid under Iceland. It is probably induced both by mantle flow and melt in the asthenosphere down to $110 \mathrm{~km}$ depth. Approximately east-west fast direction for vertically polarized shear waves (SV) in the depth range 60-110 km may indicate approximately horizontal plume head flow in a westerly direction.

In conclusion, the seismological data and their geodynamical interpretation lead to a new picture of the Icelandic lithosphereasthenosphere system in terms of the Iceland plume interacting with the migrating North-Atlantic ridge.

\section{ACKNOWLEDGMENTS}

Thanks are due to Selwyn Sacks for good academic support during the initial stage of this research and to Arthur Snoke for assistance with computer programming. The work benefited from extensive discussion with Thomas Ruedas, William Menke, Níels
Óskarsson, Thomas Forbriger, Ólafur G. Flóvenz and Wolfgang Friederich. Ólafur G. Björnsson, Niegel Watson and Philip Vogler, proof read and corrected the English. Excellent hospitality of JAMSTEC at Yokosuka in Japan to IB is greatly appreciated. Finally the authors would like to express thanks to Gillian Foulger and anonymous reviewer for constructive criticism of the manuscript in progress. Financial support by National Science Foundation (USA) (grants EAR-9316137, OCE-9402991) the Icelandic Research Center (RANNIS), the University of Iceland research fund and the German Academic Exchange Service (DAAD) is acknowledged.

\section{REFER E N CES}

Allen, R.M. et al., 2002a. Plume-driven plumbing and crustal formation in Iceland, J. geophys. Res., 107, doi:1029/2001JB000584.

Allen, R.M. et al., 2002b. Imaging the mantle beneath Iceland using integrated seismological techniques, J. geophys. Res., 107, doi: 1029/2001JB000595.

Bjarnason, I.Th., 2003. The lithosphere and asthenosphere of the Iceland hot spot, in: The 23rd General Assembly of the International Union of Geodesy and Geophysics, Abstracts B, B.137, Sapporo, Japan, 30 June11 July.

Bjarnason, I.Th., Menke, W., Flóvenz, Ó.G. \& Caress, D., 1993. Tomographic image of the mid-atlantic plate boundary in Southwestern Iceland, J. geophys. Res., 98, 6607-6622.

Bjarnason, I.Th., Wolfe, C.J., Solomon, S.C. \& Gudmundsson, G., 1996a. Initial results from the ICEMELT experiment: body-wave delay times and shear-wave splitting across Iceland, Geophys. Res. Lett., 23, 459462.

Bjarnason, I.Th., Wolfe, C.J., Solomon, S.C. \& Gudmundsson, G., 1996b. Initial results from the ICEMELT experiment: body-wave delay times and shear-wave splitting across Iceland, Geophys. Res. Lett., 23, 903.

Bjarnason, I.T., Silver, P.G., Rümpker, G. \& Solomon, S.C., 2002. Shear wave splitting across the Iceland hot spot: results from the ICEMELT experiment, J. geophys. Res., 10.1029/2001JB000916.

Brandsdóttir, B., Menke, W., Einarsson, P., White, R.S. \& Staples, R.K., 1997. Faroe-Iceland ridge experiment 2. Crustal structure of the Krafla central volcano, J. geophys. Res., 102, 7867-7886.

Buck, W.R., 1991. Modes of continental lithospheric extension, J. geophys Res., 96(B12), 20 161-20178.

Crampin, S., Volti, T., Chastin, S., Gudmundsson, A. \& Stefánsson, R., 2002. Indication of high pore-fluid pressures in a seismically-active fault zone, Geophys. J. Int., 151, F1-F5.

Darbyshire, F.A., Bjarnason, I.Th., White, R.S. \& Flóvenz, Ó.G., 1998. Crustal structure above the Iceland mantle plume imaged by the ICEMELT refraction profile, Geophys. J. Int., 135, 1131-1149.

Darbyshire, F.A., White, R.S. \& Priestley, K.F., 2000a. Structure of the crust and uppermost mantle of Iceland from combined seismic and gravity study, Earth planet. Sci. Lett., 181, 409-428.

Darbyshire, F.A., Priestley, K.F., White, R.S., Stefánsson, R., Gudmundsson, G.B. \& Jakobsdóttir, S.S., 2000b. Crustal structure of central and northern Iceland from analysis of teleseismic receiver functions, Geophys. J. Int., 143, 163-184.

Debayle, E. \& Kennett, B.L.N., 2000. Anisotropy in the Australasian upper mantle from Love and Rayleigh waveform inversion, Earth planet. Sci. Lett., 184, 339-351.

Du, Z.J. \& Foulger, G.R., 1999. The crustal structure beneath the northwest fjords, Iceland, from receiver functions and surface waves, Geophys. J. Int., 139, 419-432.

Du, Z. \& Foulger, G.R., 2001. Variation in the crustal structure across central Iceland, Geopys. J. Int., 145, 246-264.

Du, Z. \& Foulger, G.R., 2004. Surface wave waveform inversion for variation in the upper mantle structure beneath Iceland, Geophys. J. Int., 157, 305 314, doi:10.1111/j.1365-246X.2004.02202.x

Du, Z. et al., 2002. Crustal structure beneath western and eastern Iceland from surface waves and receiver functions, Geophys. J. Int., 149, 349-363. 
Dziewonski, A.M. \& Anderson, D.L., 1981. Preliminary reference Earth model, Phys. Earth planet. Int., 25, 297-356.

Ekström, G. \& Dziewonski, A.M., 1998. The unique anisotropy of the Pacific upper mantle, Nature, 394(9), 168-172.

Evans, J.R. \& Sacks, I.S., 1979. Deep structure of the Iceland Plateau, J. geophys. Res., 84, 6859-6866.

Evans, J.R. \& Sacks, I.S., 1980. Lithospheric structure in the north Atlantic from observations of Love and Rayleigh waves, J. geophys. Res., 85, $7175-7182$.

Fedorova, T., Jacoby, W.R. \& Wallner, H., 2005. Crust-mantle transition and Moho model for Iceland and surroundings from seismic, topography, and gravity data, Tectonophysics, 396, 119-140.

Flóvenz, Ó.G., 1980. Seismic structure of the Icelandic crust above layer three and the relation between body wave velocity and the alteration of the basaltic crust, J. Geophys., 47, 211-220.

Flóvenz, Ó.G. \& Sæmundsson, K., 1993. Heat flow and geothermal processes in Iceland, Tectonophysics, 22, 123-138.

Fleming, K., Martinec, Z. \& Wolf, D., 2007. Glacial-isostatic adjustment and the viscosity structure underlying the Vatnajökull Ice Cap, Iceland, Pure appl. Geophys., 164, 751-768.

Foulger, G.R., 2002. Hotspots. Plumes, or plate tectonic processes? Astron. and Geophys., 43, 6.19-6.23.

Foulger, G.R., 2006. FAST TRACK PAPER: older crust underlies Iceland, Geophys. J. Int., 165, 672-676, doi:10.1111/j.1365-246X.2006.02941.x.

Foulger, G.R. et al., 2000. The seismic anomaly beneath Iceland extends down to the mantle transition zone and no deeper, Geophys. J. Int., 142, F1-F5.

Foulger, G.R. et al., 2001. The seismic tomography shows that upwelling beneath Iceland is confined to the upper mantle, Geophys. J. Int., 146, 504-530.

Gebrande, H., Miller, H. \& Einarsson, P., 1980. Seismic structure of Iceland along RRISP-profile I, J. Geophys., 47, 239-249.

Green, D.H. \& Fallon, T.J., 1998. Pyrolite: A Ringwood concept and its current expression, in The Earths Mantle: Composition, Structure and Evolution, pp. 331-380, ed. Jackson, I.N.S., Cambridge University Press, Cambridge.

Hardarson, B.S., Fittona, J.G., Ellamb, R.M. \& Pringle, M.S., 1997. Rift relocation - a geochemical and geochronological investigation of a palaeo-rift in northwest Iceland, Earth planet. Sci. Lett., 153, 181-196, doi:10.1016/S0012-821X(97)00145-3.

Herrin, E. \& Goforth, T. 1977. Phase-matched fitlers: Application to the study of Rayleigh waves, Bull. seism. Soc. Am., 67, 1259-1275.

Herrmann, R.B. (ed.), 1984-1991. Computer Programs in Seismology, St. Louis University, St. Luis. Available at http://www.eas.slu.edu/ People/RBHerrmann/CPS330.html.

Hofton, M.A. \& Foulger, G.R., 1996a. Post-rifting anelastic deformation around the spreading plate boundary, north Iceland, 1: modeling of the 1987-1992 deformation field using a viscoelastic Earth structure, J. geophys. Res., 101, 25 403-25 421.

Hofton, M.A. \& Foulger, G.R., 1996b. Post-rifting anelastic deformation around the spreading plate boundary, north Iceland, 2: implications of the model derived from the 1987-1992 deformation field J. geophys. Res., 101, $25423-25436$.

Holbrook, W.S. et al., 2001. Mantle thermal structure and active upwelling during continental breakup in the North Atlantic, Earth planet. Sci. Lett., 190, 251-266.

Holtzman, B.K., Kohlsted, D.L., Zimmerman, M.E., Heidelback, F., Hirage, T. \& Hustoft, J., 2003. Melt segregation and strain partitioning: implications for seismic anisotropy and mantle flow, Science, 301, 12271230.

Jóhannesson, H. \& Saemundsson, K., 1998. Geological Map of Iceland, 1:500.000, Tectonics, Icelandic Institute of Natural History, Reykjavík.

Kaban, M.K., Flóvenz, O.G. \& Pálmason, G., 2002. Nature of the crustmantle transition zone and the thermal state of the upper mantle beneath Iceland from gravity modelling, Geophys. J. Int., 149, 281-299.

Kennett, B.L.N., Engdahl, E.R. \& Buland, R., 1995. Constraints on seismic velocities in the earth from travel times, Geophys. J. Int., 122, 108-124.

Karato, S. \& Jung, H., 1998. Water, partial melting and the origin of the seismic low velocity and high attenuation zone in the upper mantle. Earth planet. Sci. Lett., 157(3-4), 193-207.

Kreutzmann, A., Schmeling, H., Junge, A., Ruedas, T., Marquart, G. \& Bjarnason, I.Th., 2004. Temperature and melting of a ridge-centred plume with application to Iceland. Part II: predictions for electromagnetic and seismic observables, Geophys. J. Int., 159, 1097-1111, doi:10.1111/j.1365-246X.2004.02397.x.

Kumar, P. et al., 2005. The lithosphere-asthenosphere boundary in the North-West Atlantic region [rapid communication], EPSL, 236, 249-257, doi:10.1016/j.epsl.2005.05.029.

Langmuir, C.H., Klein, E.M. \& Plank, T., 1992. Petrological systematics of mid-ocean ridge basalts: constraints on melt generation beneath ocean ridges, in: Mantle Flow and Melt Generation at Mid-Ocean Ridges, eds Morgan, J.P., Blackman, D.K. \& Sinton, J.M., Geophysical Monograph 71, Am. Geophyp. Union.

Li, A. \& Detrick, R.S., 2003. Azimuthal anisotropy and phase velocity beneath Iceland: implication for plume-ridge interaction, Earth planet. Sci. Lett., 214, 153-165, doi:10.1016/S0012-821X(03)00382-0.

Maaløe, S. \& Jakobsson, S.P., 1980. The PT relations of a primary oceanite from the Reykjanes peninsula, Iceland, Lithos, 13, 237-246.

MacKenzie, K., McClain, J. \& Orcutt, J., 1982. Constraints on crustal structure in eastern Iceland based on extremal inversion of refraction data, J. geophys. Res., 87, 6371-6382.

Maupin, V., 1985. Partial derivatives of surface wave phase velocities for flat anisotropic models, Geophys. J. R. astr. Soc., 83, 379-398.

Maupin, V. \& Cara, M., 1992. Love-rayleigh wave incompatibility and possible deep upper mantle anisotropy in the Iberian Peninsula, PAGEOPH, 138(3), 429-444.

Menke, W., Brandsdottir, B., Jakobsdottir, S. \& Stefánsson, R., 1994. Seismic anisotropy in the crust at the mid-Atlantic plate boundary in south-west Iceland, Geophys. J. Int., 119, 783-790.

Menke, W., Brandsóttir, B., Einarsson, P. \& Bjarnason, I.Th., 1996. Reinterpretation of the RRISP-7 Iceland shear-wave profiles, Geophys. J. Int., 126, 166-172.

Menke, W., West, M., Brandsóttir, B. \& Sparks, D., 1998. Compressional and shear velocity structure of the lithosphere in north Iceland, Bull. seism. Soc. Am., 88, 1561-1571.

Mihalffy, P., Steinberger, B. \& Schmeling, H., 2004. Plume-ridge interaction in the north Atlantic influenced by large-scale mantle flow, EGU, Nice.

Mihalffy, P., Steinberger, B. \& Schmeling, H., 2008. The effect of the largescale mantle flow field on the Iceland hotspot track. Tectonophysics, 447, 5-18, doi:10.1016/j.tecto.2006.12.012.

Moorbath, S. \& Walker, G.P.L., 1965. Strontium isotope investigation of igneous rocks from Iceland, Nature, 207, 837-840.

Nishimura, C.E. \& Forsyth, D.W., 1989. The anisotropic structure of the upper mantle in the Pacific, Geophys. J., 96, 203-229.

Nunns, A.G., Talwani, M., Lorentzen, G.R., Vogt, P.R., Sigurgeirsson, T., Kristjansson, L., Larsen, H.C. \& Voppel, D., 1983. Magnetic anomalies over Iceland and surrounding seas, in Structure and Development of the Greenland-Scotland Ridge, New Methods and Concepts, pp. 661-678, eds Bott, M.H.P., Saxov, S., Talwani, M. \& Thiede, J., Plenum, New York.

Nyman, D.C. \& Landisman, M., 1977. The display-equalized filter for frequency-time analysis, Bull. seism. Soc. Am., 67, 303-404.

Pálmason, G., 1971. Crustal structure of Iceland from explosion seismology, Greinar Vísindafélag Ísl., 40, 187 pp.

Pilidou, S., Priestley, P., Debayle, E. \& Gudmundsson, Ó., 2005. Rayleigh wave tomography in the North Atlantic: high resolution images of the Iceland, Azores and Eifel mantle plumes, Lithos, 79, 453-474, doi:10.1016/j.lithos.2004.09.012.

Prestvik, T., Goldberg, S., Karlsson, H. \& Grönvold, K., 2001. Anomalous strontium and lead isotope signatures in the off-rift Öræfajökull central volcano in south-east Iceland evidence for enriched endmember(s) of the Iceland mantle plume? EPSL, 190, 211-220.

Pollitz, F.F. \& Sacks, I.S., 1996. Viscosity structure beneath northeast Iceland, J. geophys. Res., 101, 17 771-17 794.

Ruedas, T. \& Schmeling, H., 2008. Kinematic models for the thickness of oceanic crust at and near mid-oceanic spreading centers. J. geophys. Res., 113, B01402, doi:10.1029/2006JB004746. 
Ruedas, T., Schmeling, H., Marquart, G., Kreutzmann, A. \& Junge, A., 2004. Temperature and melting of a ridge-centered plume with application to Iceland, part I: dynamics and crust production, Geophys. J. Int., 158(2), 729-743.

Ruedas, T., Marquart, G. \& Schmeling, H., 2007. Iceland: The current picture of a ridge-centred mantle plume, in Mantle Plumes-A Multidisciplinary Approach, pp. 71-126, eds Ritter, J., Christensen, U.R., Springer, Berlin.

Russell, D.R., Herrmann, R.B. \& Hwang, H.J., 1988. Application of frequency variable filters to surface wave amplitude analysis, Bull. seism. Soc. Am., 78, 339-354.

Saemundsson, K., 1980. Outline of the geology of Iceland, Jökull, 29, 7-28.

Schlindwein, V., 2001. Azimuthal variation of the $P$ phase in Icelandic receiver functions, Research note, Geophys. J. Int., 144, 221-230.

Schlindwein, V., 2006. On the use of teleseismic receiver functions for studying the crustal structure of Iceland, Geophys. J. Int., 164, 551-568.

Schmeling, H., 2006. A model of episodic melt extraction for plumes, J. geophys. Res., 111, B03202, doi:10.1029/2004JB003423.

Schmeling, H. \& Marquart, G., 2008. Crustal accretion and dynamic feedback on mantle melting of a ridge centred plume: the Iceland case. Tectonophysics, 447, 31-52, doi:10.1016/j.tecto.2006.08.012.

Schutt, D.L. \& Lesher, C.E., 2006. Effects of melt depletion on the density and seismic velocity of garnet and spinel lherzolite, J. geophys. Res., 111, B05401, doi:10.1029/2003JB002950.

Smallwood, J.R., White, R.S. \& Staples, R.K., 1998. Deep crustal reflectors under Reydarfjördur, eastern Iceland: crustal accretion above the Iceland mantle plume, Geophys. J. Int., 134(1), 277-290, doi:10.1046/j.1365246x.1998.00593.x.

Sigmundsson, F., 1991. Post-glacial rebound and asthenosphere viscosity in Iceland, Geophys. Res. Lett., 18, 1131-1134.

Smith, W.H.F. \& Sandwell, D.T., 1997. Global seafloor topography from satellite altimetry and ship depth soundings, Science, 277, 1957-1962.

Staples, R.K., White, R.S., Brandsdóttir, B., Menke, W., Maguire, P.K.H. \& McBride, J.H., 1997. Faroe-Iceland Ridge experiment 1. Crustal structure of northeast Iceland, J. geophys. Res., 102, 7849-7866.

Stefánsson, R. et al., 1993. Earthquake prediction research in the South Iceland Seismic Zone and the SIL project, Bull. seism. Soc. Am., 83, 696-716.

Tryggvason, A., Rögnvaldsson, S.Th. \& Flóvenz, Ó.G., 2002. Threedimensional imaging of the P- and S-wave velocity structure and earthquake locations beneath Southwest Iceland, Geophys. J. Int., 151, 848866.

Turcotte, D.L. \& Schubert, G., 1982. Geodynamics, applications of continuum physics to geological problems, $450 \mathrm{pp}$.

Vinnik, L.P., Foulger, G.R. \& Du, Z., 2005. FAST TRACK PAPER: seismic boundaries in the mantle beneath Iceland: a new constraint on temperature, Geophys. J. Int., 160, 533-538, doi:10.1111/j.1365-246X.2005.02529.x.

Weir, N.R.W., White, R.W., Brandsdóttir, B., Einarsson, P., Shimamura, H., Shiobara, H. \& the, RISE Fieldwork Team, 2001. Crustal structure of the northern Reykjanes Ridge and the Reykjanes peninsula, southwest Iceland, J. geophys. Res., 106, 6347-6368.

White, R.S., 1997. Rift-plume interaction in the North Atlantic, Phil. Trans. R. Soc. Lond. A, 355, 319-339.

Wolfe, C.J., Bjarnason, I.Th., VanDecar, J.C. \& Solomon, S.C., 1997. Seismic structure of the Iceland mantle plume, Nature, 385, 245-247.

Yoshizawa, K. \& Kennett, B.L.N., 2002. Determination of the influence zone for surface wave paths, Geophys. J. Int., 149, 440-453.

Xue, M. \& Allen, R.M., 2005. Asthenospheric channeling of the Icelandic upwelling: evidence from seismic anisotropy, Earth planet. Sci. Lett., 235, 167-182.

Zverev, S.M., Litvinenko, I.V., Pálmason, G., Yaroshevskaya, G.A., Osokin, N.N. \& Akhmetjev, M.A., 1980. A seismic study of the rift zone in northern Iceland, J. Geophys., 47, 191-201.

\section{APPENDIX}

In spite of the simplicity of the regional waves several processing steps were necessary to obtain a stable and smooth interstation dis-
Table A1. Starting model 8f.

\begin{tabular}{lccc}
\hline & Upper-midcrust & Lower crust & Mantle \\
\hline Depth to top $(\mathrm{km})$ & 0 & 10 & 28 \\
Thickness $(\mathrm{km})$ & 10 & 18 & $340+1 / 2$ space \\
No. of layers & 5 & 9 & 24 \\
$S$ velocity $\left(\mathrm{km} \mathrm{s}^{-1}\right)$ & $2.31-3.62$ & $3.72-4.06$ & $4.09-4.32$ \\
$P$ velocity $\left(\mathrm{km} \mathrm{s}^{-1}\right)$ & $4.11-6.45$ & $6.64-7.25$ & $7.30-7.70$ \\
Density $\left(\mathrm{g} \mathrm{cm}^{-3}\right)$ & $2.52-2.66$ & $2.93-3.10$ & $3.10-3.28$ \\
$Q_{S}$ & 50 and 200 & 200 and 100 & 100 \\
\hline
\end{tabular}

persion over the wide period range analysed. The display-equalized frequency-time-analysis method (FTAN) of Nyman \& Landisman (1977) was used to construct an estimate of the fundamental mode group velocity dispersion between the source and receiver. The phase-matched filter technique of Herrin \& Goforth (1977), implemented by Russell et al. (1988) in Herrmann (1984-1991), was used to filter out multipath arrivals and higher modes using the previously determined FTAN group velocity dispersion as a starting filter (model). A first estimate of the interstation dispersion was made by taking a spectral phase difference of the waveforms at the two stations with smoothing of spectral holes. This estimate, and later a good average estimate between station pairs, was used to disperse the waves at the one station to the other and then a smoother and improved estimate is calculated by cross correlating the two station traces with the xspcrs method of Herrmann (1984-1991).

The inversion requires a starting model of seismic velocities and densities. The shear velocity is the free variable that is inverted for. A constant ratio of compressional to shear velocity $\left(V_{p} / V_{s}\right)$ was chosen a priori. The ratio $V_{p} / V_{s}=1.785$ was used at all depths. It was thought to be a reasonable intermediate between the 1.76 ratio found for the upper half of the Icelandic crust (Menke et al. 1996) and expected higher ratio for a hotter Icelandic mantle than an average global upper mantle ratio of 1.79 (e.g. ak135 of Kennett et al. 1995). However, with hindsight a ratio $V_{p} / V_{s}=1.785$, is a reasonable a priori value for the Icelandic crust, and a ratio $>1.80$ for the mantle. The starting density structure was based on (Kaban et al. 2002, Fig. A1, Table A1). Layers with constant velocity are inverted for using stochastic damping, that controls the size of the change in the model vector in each iteration, but does not produce particularly smooth models. Higher damping was used in the initial iterations, but decreased in the final ones, allowing for increased roughness of the model and better fit to the data. Vertical smoothing was done with variable layer thickness. Layer thicknesses range from $2 \mathrm{~km}$ in the top 36 to $40 \mathrm{~km}$ thick in the bottom $120 \mathrm{~km}$ of the models, with intermediate thicknesses in between. All velocity models are presented with linear interpolation between layer velocities, to give them smoother and more realistic appearance.

The starting velocity model was designed to be as smooth as possible, with the crustal part loosely following crustal refraction models of the Icelandic crust, but without a Moho. A sharp velocity discontinuity (10-20 per cent) like a Moho in a starting model, tends to be retained by the inversion process. A good a priori information should therefore be available before adopting such an inert feature in a starting model. The nature of the $\mathrm{BCM}$ (or transition) in Iceland, is still being debated. A number of refraction experiments have found $P m P$ like reflections around the island, but fewer have found the corresponding Pn phase. None have constrained well the actual velocity jump by, for example, modelling at the same time observed Pn velocity and PmP amplitudes. Several receiver function studies have been done to study the crust and mantle lid of Iceland 


\section{Starting model $8 f$}

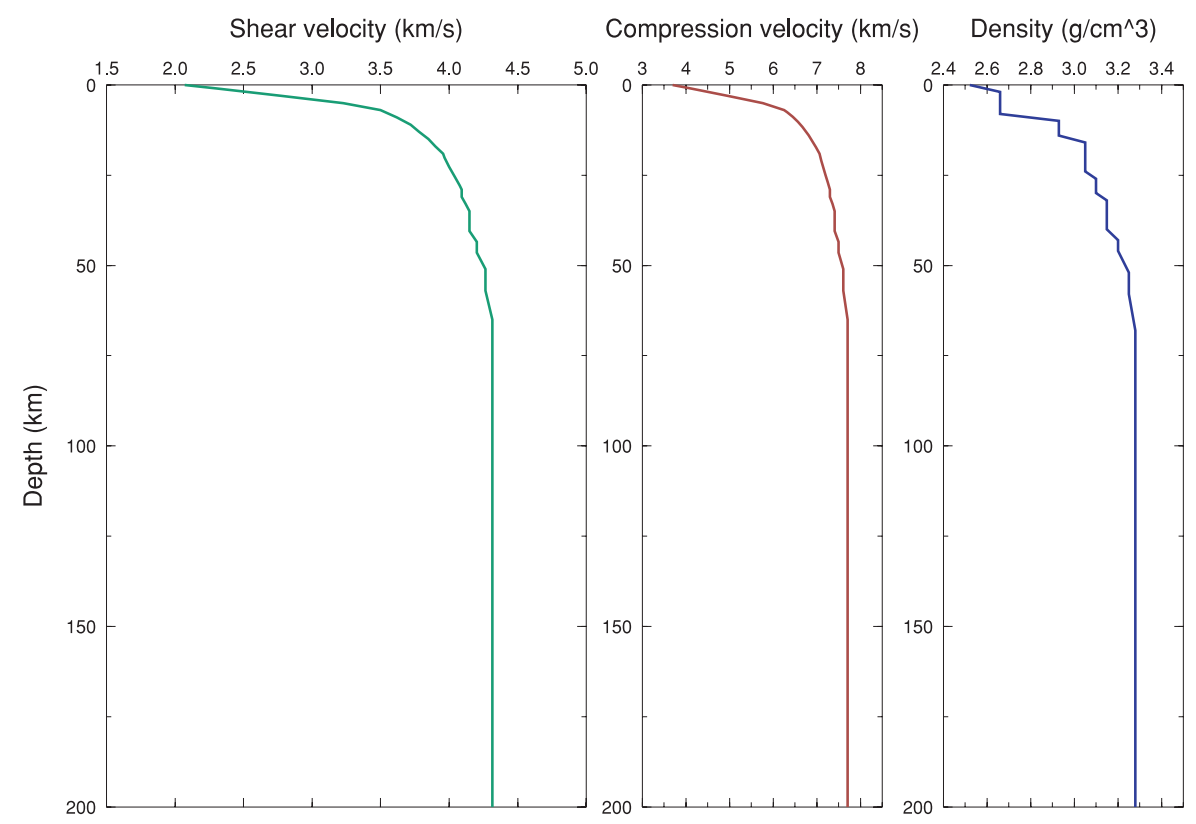

Figure A1. The starting model, compressional velocity $\left(V_{P}\right)$, shear velocity $\left(V_{S}\right)$ and density $(\rho)$.

(Du \& Foulger 1999; Darbyshire et al. 2000b; Schlindwein 2001; Du \& Foulger 2001; Schlindwein 2006). A minority of them model receiver functions with a significant Moho (i.e. with 10-20 per cent discontinuity). In this study, starting models were designed with a 10 per cent Moho jump at 28 and at $36 \mathrm{~km}$ depth and a rather small $S$-velocity gradient $\left(0.005 \mathrm{~s}^{-1}\right)$ in the lower lower crust. The fit of the Love wave dispersion data is very similar with Moho or without a Moho starting model, but in some cases significantly worse with a Moho starting model for Rayleigh dispersion. Starting models with a Moho also gave solutions with large velocity inversion in the lower crust, a structure that has not been observed with refraction measurements. The final choice was a starting model without a Moho.

To evaluate the effectiveness of the method designed here to estimate crustal thickness, synthetic tests were made on two classes of models, with thin ( $40 \mathrm{~km})$ and thick $(60-85 \mathrm{~km})$ lithosphere. The models were designed with a BCM at several different depths, with rather small Moho velocity jump (3-5 per cent). Realistic noise was added to the dispersion response of these models, and inverted back to velocity structure. There is a positive correlation, between the crustal thickness of the models and the estimated crustal thickness (Fig. A2). The correlation coefficients are 0.67 and 0.69 , the higher for the thick lithosphere models. With the limited number of test samples, linear relationship between the model thickness and the solution thickness is not statistically significant, but neither is such a relationship rejected. On average the estimated crustal thickness is underestimated by 1.5 and $2.4 \mathrm{~km}$ for the thick and thin lithosphere models, respectively.

All of the measured paths contain dispersion measurements from both direction (i.e. with approximately opposite back-azimuths). The NW path contains the most uneven direction distribution. However, none of the paths have enough measurements from both directions to make a test of statistical difference in dispersion depending on dipolar direction, over the whole measured period range. The $\mathrm{W}$ path comes closest for such a comparison, with very close agreement between most of the periods that could be compared from both directions.

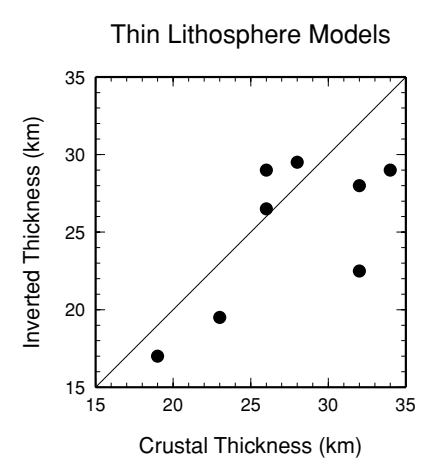

Thick Lithosphere Models

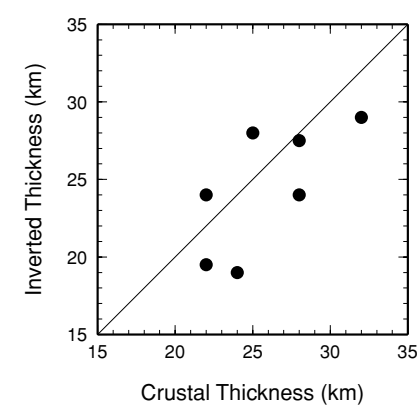

Figure A2. Synthetic test for crustal thickness estimate. Better estimates are archived for models with thick lithosphere $(60-85 \mathrm{~km})$ than thin lithosphere (40 km). In both cases crustal thickness is underestimated on average by 1.5 and $2.4 \mathrm{~km}$, respectively. 